\title{
Review
}

\section{Review of Silicon Carbide Processing for Power MOSFET}

\author{
Catherine Langpoklakpam ${ }^{1}$, An-Chen Liu ${ }^{1}$, Kuo-Hsiung Chu ${ }^{1}$, Lung-Hsing Hsu ${ }^{1,2}{ }^{\circledR}$, Wen-Chung Lee ${ }^{1,2}$, \\ Shih-Chen Chen ${ }^{3}$, Chia-Wei Sun ${ }^{1}$, Min-Hsiung Shih ${ }^{4}$, Kung-Yen Lee ${ }^{5,6}$ and Hao-Chung Kuo ${ }^{1,3, *(1)}$
}

1 Department of Photonics, Institute of Electro-Optical Engineering, College of Electrical and Computer Engineering, National Yang Ming Chiao Tung University, Hsinchu 30010, Taiwan; cath01.ee09@nycu.edu.tw (C.L.); arsen.liou@gmail.com (A.-C.L.); martinchu.eo05g@g2.nctu.edu.tw (K.-H.C.); alger.99g@g2.nctu.edu.tw (L.-H.H.); vincent.lee67@gmail.com (W.-C.L.); chiaweisun@nctu.edu.tw (C.-W.S.)

2 Industrial Technology Research Institute, No. 195, Sec. 4, Chung Hsing Rd., Chutung, Hsinchu 31040, Taiwan

3 Semiconductor Research Center, Hon Hai Research Institute, Taipei 11492, Taiwan; gary.sc.chen@foxconn.com

4 Research Center for Applied Sciences (RCAS), Academia Sinica, Taipei 11529, Taiwan; mhshih@gate.sinica.edu.tw

5 Department of Engineering Science and Ocean Engineering, National Taiwan University, Taipei 10617, Taiwan; kylee@ntu.edu.tw

6 Advanced Research Centre for Green Materials Science and Technology, National Taiwan University, Taipei 10617, Taiwan

* Correspondence: hckuo@faculty.nctu.edu.tw; Tel.: +886-3-571-2121 (ext. 31986)

Citation: Langpoklakpam, C.; Liu, A.-C.; Chu, K.-H.; Hsu, L.-H.; Lee, W.-C.; Chen, S.-C.; Sun, C.-W.; Shih, M.-H.; Lee, K.-Y.; Kuo, H.-C. Review of Silicon Carbide Processing for Power MOSFET. Crystals 2022, 12, 245. https://doi.org/10.3390/ cryst12020245

Academic Editor: Giancarlo Salviati

Received: 3 December 2021

Accepted: 8 February 2022

Published: 11 February 2022

Publisher's Note: MDPI stays neutral with regard to jurisdictional claims in published maps and institutional affiliations.

Copyright: (C) 2022 by the authors. Licensee MDPI, Basel, Switzerland. This article is an open access article distributed under the terms and conditions of the Creative Commons Attribution (CC BY) license (https:/ / creativecommons.org/licenses/by/ $4.0 /)$.

\begin{abstract}
Owing to the superior properties of silicon carbide ( $\mathrm{SiC})$, such as higher breakdown voltage, higher thermal conductivity, higher operating frequency, higher operating temperature, and higher saturation drift velocity, $\mathrm{SiC}$ has attracted much attention from researchers and the industry for decades. With the advances in material science and processing technology, many power applications such as new smart energy vehicles, power converters, inverters, and power supplies are being realized using $\mathrm{SiC}$ power devices. In particular, $\mathrm{SiC}$ MOSFETs are generally chosen to be used as a power device due to their ability to achieve lower on-resistance, reduced switching losses, and high switching speeds than the silicon counterpart and have been commercialized extensively in recent years. A general review of the critical processing steps for manufacturing SiC MOSFETs, types of $\mathrm{SiC}$ MOSFETs, and power applications based on $\mathrm{SiC}$ power devices are covered in this paper. Additionally, the reliability issues of SiC power MOSFET are also briefly summarized.
\end{abstract}

Keywords: silicon carbide (SiC); silicon (Si); power devices; SiC MOSFETs; on-resistance; breakdown voltage

\section{Introduction}

The development of power electronics technology has always been towards achieving higher power density, higher efficiency, and integrating many systems [1,2]. Power semiconductor devices (power devices) play an important role in this development. Power devices are used for controlling electric energy precisely, with high efficiency and reliability from the source to load, depending on the load demand. Over the last 50 years, the advancements of power devices have been primarily due to Si-based power devices. However, due to limitations of the intrinsic physical properties of $\mathrm{Si}$, devices based on $\mathrm{Si}$ cannot be used for future power devices. Hence, researchers have aimed to find alternative materials for replacing $\mathrm{Si}$ in power devices [3]. The introduction of wide-bandgap (WBG) semiconductor materials such as silicon carbide $(\mathrm{SiC})$ and gallium nitride $(\mathrm{GaN})$ materials have been a revolutionary development in the field of power devices [3,4]. The superior material properties of WBG materials, such as higher dielectric strength, higher saturation drift velocity, and the ability to operate in harsh environments, make the materials favorable for power devices [5]. GaN-based devices are mainly used for high-frequency applications, while $\mathrm{SiC}$-based devices are used for high voltage power applications. The larger critical electric field, higher thermal conductivity, and higher breakdown voltage enable SiC-based 
devices to operate at higher current density, higher temperature, and higher blocking voltage [4,6-8]. Hence, SiC-based power components have been a topic for extensive research for high voltage/power applications for more than a decade. Moreover, $\mathrm{SiC}$ is more mature in terms of the quality of the crystal [9], the existence of large wafers [10], and is readily available in the market [11]. In addition, the material cost of $\mathrm{SiC}$ is much lesser than that of $\mathrm{GaN}$ [12], and the processing lines of SiC-based devices have great compatibility with that of Si-based devices.

\subsection{SiC Materials Properties}

$\mathrm{SiC}$ was discovered by professor Jons Jakob Berzelius in 1823 at the Karolinska Institute in Stockholm [13]. SiC exists in different crystalline structures, depending on the stacking sequence, and this phenomenon is known as polytypism, where each structure is known as a polytype of $\mathrm{SiC}$. Hence, $\mathrm{SiC}$ is a classical polytypic substance existing in more than 250 polytypes $[14,15]$. The most common research polytypes for $\mathrm{SiC}$ devices are $6 \mathrm{H}-\mathrm{SiC}$, $4 \mathrm{H}-\mathrm{SIC}$, and $3 \mathrm{C}-\mathrm{SiC}$. The crystal structures of $4 \mathrm{H}, 6 \mathrm{H}$, and $3 \mathrm{C} \mathrm{SiC}$ polytypes are shown in Figure 1 [16]. Among the polytypes, $6 \mathrm{H}-\mathrm{SiC}$ and $4 \mathrm{H}-\mathrm{SiC}$ are the most preferred polytypes, especially for device production, as they can make a large wafer and are also commercially available. For high power, high temperature, and high-frequency device applications, $4 \mathrm{H}-\mathrm{SiC}$ is the most used and established-material due to its high electron mobility [17,18], higher bandgap, higher critical electric field [19], and shallower ionization energy of dopant [20], along with the availability of the single crystalline wafer. In addition, $4 \mathrm{H}-\mathrm{SiC}$ does not exhibit anisotropy electron mobility, whereas $6 \mathrm{H}-\mathrm{SiC}$ does [21]. Hence, $4 \mathrm{H}-\mathrm{SiC}$ has been developed exclusively and is also more readily available $[9,22]$.

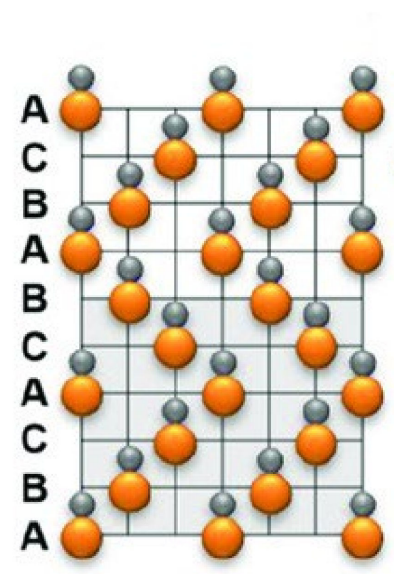

$6 \mathrm{H}-\mathrm{SiC}$

\section{Hexagonal}

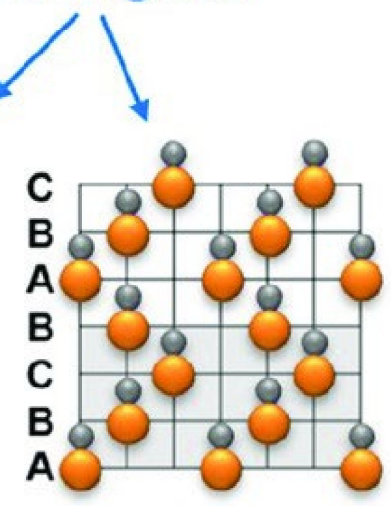

4H-SiC
Carbon

Silicon

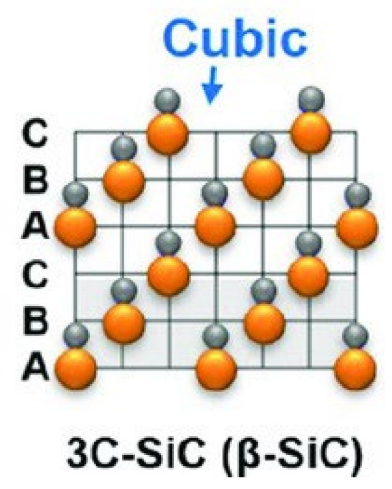

Figure 1. The staking sequences of $\mathrm{SiC}$ polytypes: $4 \mathrm{H}-\mathrm{SiC}, 6 \mathrm{H}-\mathrm{SiC}$, and $3 \mathrm{C}-\mathrm{SiC}$ [16].

The comparison of three polytypes of $\mathrm{SiC}$ with $\mathrm{Si}$ is given in Table 1 [20]. Each polytype exhibits different electronics properties, and the bandgap energy of polytypes are larger than that of Si and remains the same at $1000 \mathrm{~K}$ [20]. Moreover, the intrinsic carrier concentration of the polytypes is much lower than that of the $\mathrm{Si}$, which makes $\mathrm{SiC}$ a suitable candidate for high-temperature applications. This is because, at high temperatures, the material properties undergo changes such as decreasing the energy bandgap and increasing carrier concentration, which affect the device performance [23]. Therefore, a WBG material with a low intrinsic carrier concentration is preferred for high-temperature power applications. In addition, the high thermal conductivity of $\mathrm{SiC}$ allows the transfer of heat more efficiently than the other semiconductors, which further enhances the performance of the device [24]. For semi-insulating $\mathrm{SiC}$ with low impurity, a very high thermal conductivity of about $500 \mathrm{~W} / \mathrm{m}-\mathrm{K}$ was achieved [25]. 
Table 1. Comparison of material parameters of polytypes of SiC and Si [20].

\begin{tabular}{|c|c|c|c|c|}
\hline Material Parameters & $4 \mathbf{H}$ & $6 \mathrm{H}$ & $3 C$ & Si \\
\hline Energy bandgap at $300 \mathrm{~K}(\mathrm{eV})$ & 3.26 & 3.03 & 2.3 & 1.12 \\
\hline Lattice constant at $300 \mathrm{~K}(\mathrm{~A})$ & 3.076 & 3.081 & 4.349 & 3.84 \\
\hline Critical electric field $(\mathrm{V} / \mathrm{cm})$ & $2.2 \times 10^{6}$ & $2.5 \times 10^{6}$ & $2 \times 10^{6}$ & $2.5 \times 10^{5}$ \\
\hline Saturated electron drift velocity $(\mathrm{cm} / \mathrm{s})$ & $2 \times 10^{7}$ & $2 \times 10^{7}$ & $2.5 \times 10^{7}$ & $1.0 \times 10^{7}$ \\
\hline Thermal conductivity $\left(\mathrm{W} / \mathrm{cm}^{-1} \mathrm{~K}^{-1}\right)$ & $3.0-3.8$ & $3.0-3.8$ & $3-4$ & 1.5 \\
\hline Intrinsic carrier concentration $\left(\mathrm{cm}^{-3}\right)$ & $10^{-7}$ & $10^{-5}$ & 10 & $10^{10}$ \\
\hline $\begin{array}{l}\text { Electron Mobility at } \mathrm{N}_{\mathrm{D}}=10^{16}\left(\mathrm{~cm}^{2} / \mathrm{V}-\mathrm{s}\right) \\
\qquad(\| \mathrm{c} \text {-axis })\end{array}$ & 900 & 60 & 750 & 1400 \\
\hline
\end{tabular}

Moreover, the higher critical electric field of $\mathrm{SiC}$, at least by one order magnitude than $\mathrm{Si}$, helps $\mathrm{SiC}$ devices to have a thinner and highly doped drift region for the same breakdown voltage, which further reduces the specific on-resistance $\left(R_{\mathrm{on}, \mathrm{sp}}\right)$. Thus, a smaller die size can be achieved [26]. The outstanding chemical properties of $\mathrm{SiC}$, such as higher melting temperature $\left(2800^{\circ} \mathrm{C}\right)$, higher chemical inertness, and higher radiation resistance [27], along with its impressive mechanical properties, especially the hardness $\left(2480 \mathrm{~kg} / \mathrm{mm}^{2}\right)$ and high wear resistance value (9.15) [28], make SiC an excellent candidate for use in high temperature and harsh environmental conditions, ranging from highly erosive to highly corrosive environments. Along with the abovementioned properties of $\mathrm{SiC}$, some other characteristics of $\mathrm{SiC}$ that are also useful in power devices include the ability to grow homoepitaxially without mismatch, achieving both p- and n-type conductivity by doping, the availability of large substrates, and the ability to grow oxide film thermally on both Si and C faces [29].

\subsection{SiC Power Devices}

A semiconductor device is said to be a power device if it is used as a rectifier or a switch in power electronics. Power devices are the heart of the power electronics system. Power devices were first introduced in 1950 [30]. Since then, many Si power devices have been introduced, namely, bipolar power transistor (BPT or BIT), insulated gate bipolar transistor (IGBT), gate turn-off thyristor (GTO), static induction transistor (SIT), and power MOSFET. However, despite achieving numerous advancements, Si power devices had reached their performance limitation. The groundbreaking developments in power devices are due to the introduction of WBG-based power devices due to the excellent material properties of WBG materials, as mentioned above. Most of the SiC-based power rectifiers and power switches for high voltage applications are designed as vertical devices based on semi-conducting substrates. In contrast, some other SiC-based high-power RF devices, such as metal-semiconductor field-effect transistors (MESFETs), are designed as a horizontal device and are generally based on a semi-insulating substrate [31,32].

The main advantages of $\mathrm{SiC}$ power devices over Si power devices are as follows [33]: First, improved voltage capability. The breakdown voltage of SiC SBDs is able to achieve around $1700 \mathrm{~V}$, which is much higher than that of $200 \mathrm{~V}$ Si-based SBDs. Chips based on a $\mathrm{SiC}$ diode were able to obtain a breakdown voltage of about $20 \mathrm{kV}$, which is almost equivalent to that of a high-pressure $\mathrm{Si}$ stack. The breakdown voltage of SiC MOSFETs is about $10 \mathrm{kV}$, whereas it is $1 \mathrm{kV}$ for the Si MOSFETs. Moreover, the complexity, as well as the size of $\mathrm{SiC}$ devices, can be reduced drastically compared to that of $\mathrm{Si}$ devices as the total parallel and series components of $\mathrm{SiC}$ devices can be minimized to 1/10th times of $\mathrm{Si}$ devices, thus increasing the reliability of $\mathrm{SiC}$ devices. Second, the outstanding switching performance of $\mathrm{SiC}$ devices. On comparing with $\mathrm{Si}$ devices, $\mathrm{SiC}$ devices have a negligible reverse recovery rate at the same voltage level. Hence, $\mathrm{SiC}$ devices are preferred for highfrequency operations, i.e., tens of $\mathrm{MHz}$. Third, generally, the $\mathrm{SiC}$ devices tend to have a positive temperature coefficient when compared with $\mathrm{Si}$ devices and can achieve a larger 
current by using parallel chips. Therefore, designing a device with a higher voltage, the higher current becomes much more convenient.

Among the power devices, the power MOSFET is one of the most common power devices due to its fast switching speed, low gate drive power, as well as the capability of withstanding both high current and voltage applications simultaneously without any destructive failure [34]. On comparing SiC-based power MOSFET and Si-based power MOSFET, $\mathrm{SiC}$ power MOSFET can achieve a $\mathrm{R}_{\mathrm{on} \text {, sp }}$ much lower than that of the Si counterpart, which helps in achieving a smaller parasitic capacitance as well as higher switching speed [35]. Therefore, a power device based on $\mathrm{SiC}$ can achieve lower conduction and switching loss for a large range of blocking voltages [36]. In addition, the major advantage of SiC MOSFET over Si MOSFET is that as the temperature rises from 25 to $135{ }^{\circ} \mathrm{C}$, the on-resistance of $\mathrm{SiC}$ MOSFET is increased by $20 \%$, whereas it increased by $250 \%$ for $\mathrm{Si}$ MOSFET [37].

$\mathrm{SiC}$ power MOSFETs have made tremendous progress since the first $\mathrm{SiC}$ device appeared in 2001 [35]. The evolution of the commercialization of SiC power devices is shown in Figure 2 [38]. Currently, the main suppliers of $\mathrm{SiC}$ power devices are Cree/Wolfspeed, Microsemi, Infineon, GeneSiC, ST, Mitsubishi, and ROHM [39]. Additionally, according to Yole, a research organization of the market, these companies together share $80 \%$ of the $\mathrm{SiC}$ power semiconductor market. The most common commercially available $\mathrm{SiC}$ power devices include SiC Schottky diodes, SiC JFETs, SiC BJTs, and SiC MOSFETs [35]. At present, some of the highest voltage/current rated SiC-based commercially available devices are (a) SiC Schottky diodes with a rating of $1.7 \mathrm{kV} / 25 \mathrm{~A}$, (b) discrete SiC MOSFETs with $1.7 \mathrm{kV} / 72 \mathrm{~A}$, (c) SiC MOSFET modules with $1.7 \mathrm{kV} / 225$ A from CREE/Wolfspeed, and (d) SiC BJT modules with $1.7 \mathrm{kV} / 160 \mathrm{~A}$ from GeneSiC [39]. The SiC device that is commercially available for high temperatures is the $210{ }^{\circ} \mathrm{C} \mathrm{SiC} \mathrm{BJTs} \mathrm{with} \mathrm{a} \mathrm{voltage/current}$ rating of $600 \mathrm{~V} / 20 \mathrm{~A}$ from GeneSIC.

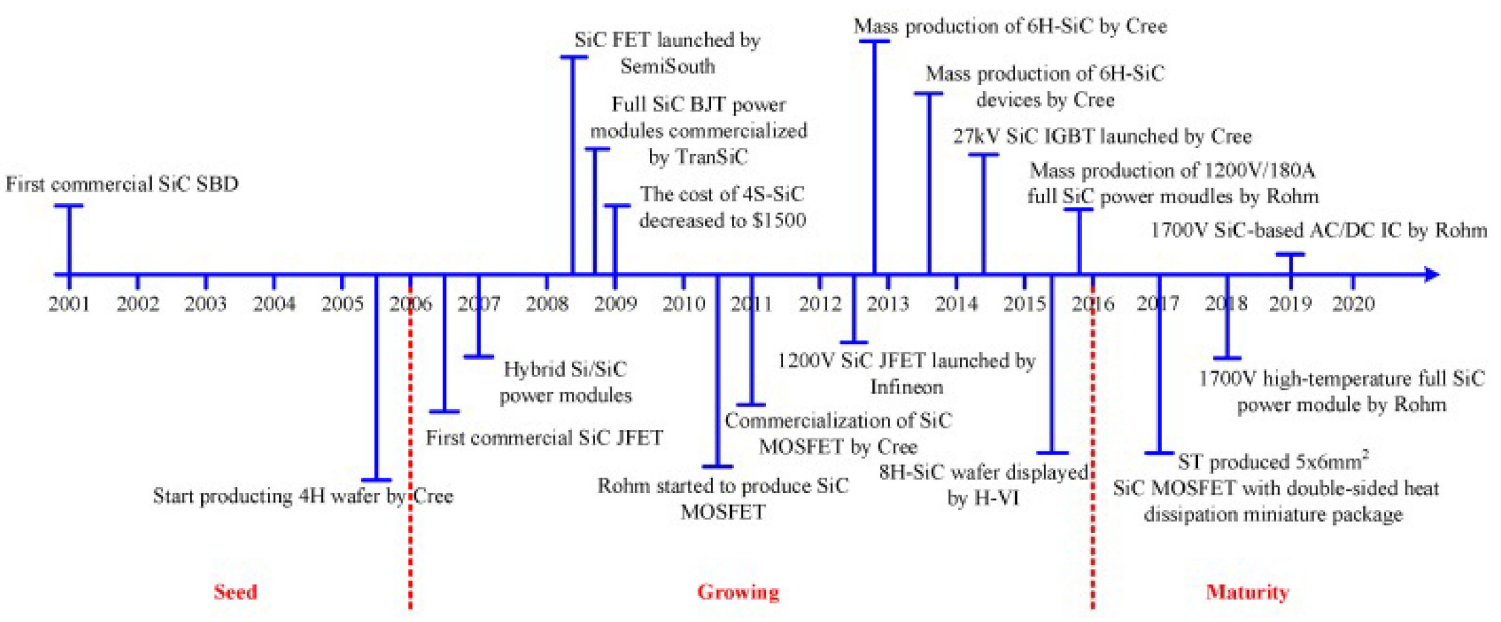

Figure 2. The development of SiC-based devices over the year [38].

The benchmark plot of various $\mathrm{SiC}$ power devices on breakdown voltage (BV) and $R_{o n, s p}$ of the various SiC power devices is shown in Figure 3. This plot represents the intrinsic capability of the device or FOM from the conduction point of view. The data of the $\mathrm{SiC}$ devices were collected from different articles [3,40-81]. From the plot, it is observed that most of the $\mathrm{SiC}$ power devices are able to perform beyond the limits of $\mathrm{Si}$, indicating the advantages of the $\mathrm{SiC}$ power devices over $\mathrm{Si}$ counterparts. Though $\mathrm{SiC}$ devices are not far from reaching their limit, there is still plenty of room for some of the $\mathrm{SiC}$ devices to improve their performances. Additionally, due to the strong conductivity modulation of SiC GTOs and PIN diodes, these devices are able to surpass the SiC limit. On comparing theoretical limits of $\mathrm{SiC}$ and $\mathrm{GaN}, \mathrm{GaN}$ limits show a better trade-off between the breakdown voltage and on-resistance. However, GaN-based devices are mainly employed for high-speed 
lower voltage applications, and, due to lower thermal conductivity than $\mathrm{SiC}, \mathrm{SiC}$-based devices are preferred for high-temperature applications.

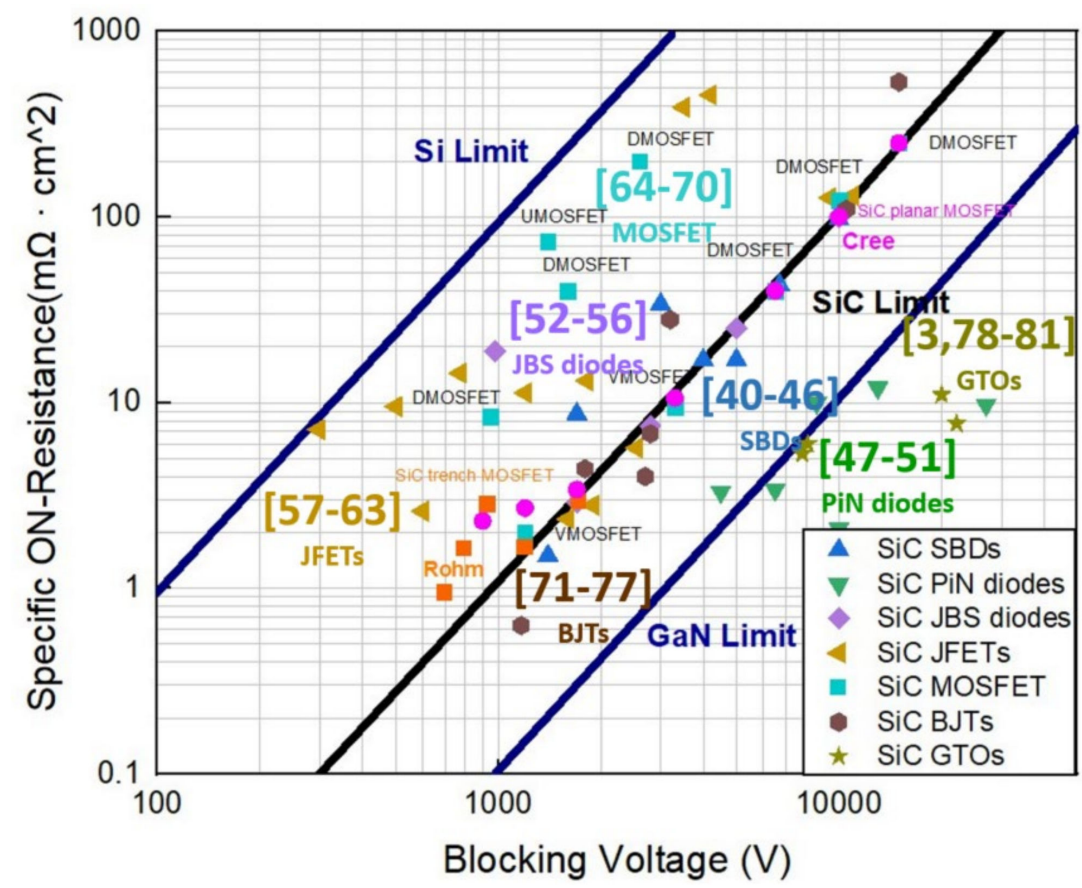

Figure 3. The benchmarking plot on specific on-resistance and breakdown voltage for various $\mathrm{SiC}$ power devices [3,40-81].

\subsection{SiC Applications}

The high-performance capabilities of $\mathrm{SiC}$ power devices provide a significant improvement in the existing systems, enabling new power applications. In addition, the outstanding material and chemical properties of $\mathrm{SiC}$, namely, high thermal conductivity, high breakdown electric field, low intrinsic carrier concentration, and high chemical inertness, make $\mathrm{SiC}$-based devices favorable devices for implementing in high-temperature electronics as well as in thermal sensors that can also be used in harsh environments [82]. Moreover, the lower on-resistance and the lower output capacitance of $\mathrm{SiC}$ MOSFET makes it an appropriate choice to be used in switching designs such as three-phase inverters, digital power supplies, and also for electronic AC-to-DC or DC-to-DC converters [31]. In addition, the reduced switching losses of $\mathrm{SiC}$ devices also improve the switching frequencies of the converters. Hence, $\mathrm{SiC}$ power devices play an important role in high-performance power device applications.

At present, SiC-based converters are used in solar inverters [83,84], EV/HEV drivers (e.g., SiC MOSFETs at Tesla Model 3 EVs) [85-87], railway traction inverters [88], high voltage applications [89], and uninterrupted power supplies (UPSs) [90]. The cost of a solar inverter was reduced by $20 \%$ of the power by using $\mathrm{SiC}$ diodes and $\mathrm{SiC} \mathrm{JFETs} \mathrm{[91].}$ Figure 4 illustrates the classification of various types of applications based on Si and WBG devices [5]. As seen in the figure, Si devices are used for lower power and lower frequency applications, while GaN-based devices are used for lower voltage and lower power highfrequency applications such as data centers and consumer systems; $\mathrm{SiC}$ devices are used for higher power, higher voltage switching power applications such as trains, electric vehicles and their battery chargers, and industrial automation. 


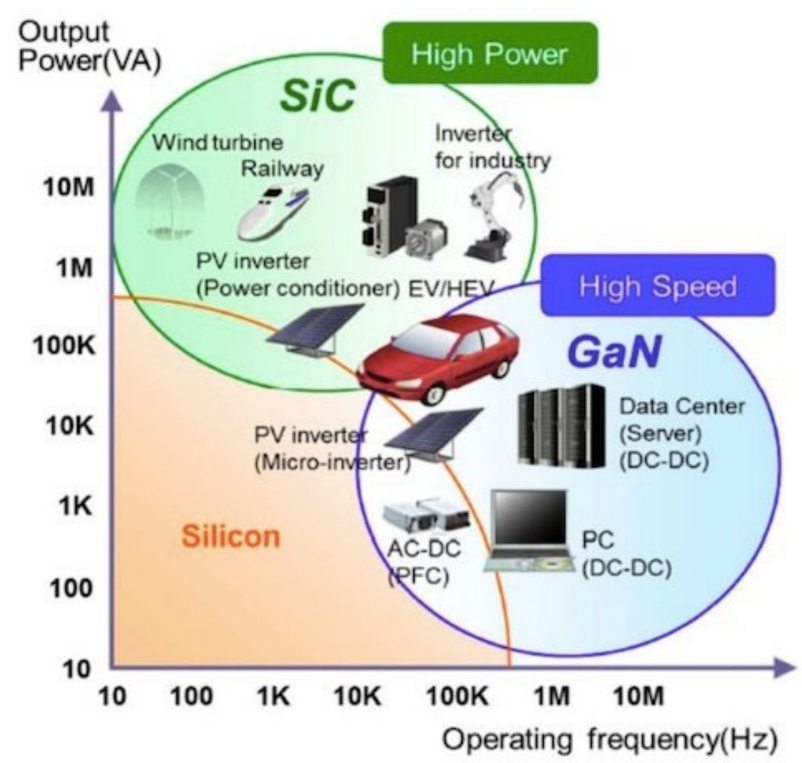

Figure 4. Applications based on WBG materials. Image used courtesy of Georgia Tech.

$\mathrm{SiC}$ power devices also provide significant help in the rising demand for photovoltaic energy. The photovoltaic energy source needs fast switching, low loss, high power, and a reliable device that improves efficiency, reliability, and power density. The desired performances have been achieved by implementing $\mathrm{SiC}$ power devices [92]. $\mathrm{SiC}$ power devices are also used for developing power modules. The $\mathrm{SiC}$ power modules were able to achieve a voltage/ampere rating range from $1.2 \mathrm{kV}-3.3 \mathrm{kV} / 70 \mathrm{~A}-800 \mathrm{~A}$, which is suitable for electric vehicle applications (EVs) such as onboard chargers, DC-DC power converters, and motor drives [93]. Smart EVs are an advanced class of vehicles that can reduce the emission of carbon dioxide up to $43 \%$ compared with diesel-based vehicles [94]. A $1.2 \mathrm{kV}$ $\mathrm{SiC}$ MOSFETs developed by Wolfspeed's was able to replace the IGBT transistors used in the circuit topologies of the EVs battery charging system; the new system was able to manage a wide range of voltage, ranging from 200 to $800 \mathrm{~V}$. Moreover, the new system was able to reduce power losses by $40 \%$, increase power density by $50 \%$, and also manage the bidirectional charging or discharging process [95].

This paper reviews the critical process steps of the fabrication process for $\mathrm{SiC}$ power devices, which include substrate formation, epitaxy layer, ion implantation, and oxidation. The most common types of SiC power MOSFETs, such as planar and trench MOSFET and superjunction MOSFET, are also discussed. Finally, the review is concluded by briefly discussing the reliability issues of SiC MOSFETs.

\section{SiC Critical Step}

One of the most important steps that play an important role in improving the performance of $\mathrm{SiC}$ power devices is the device fabrication process flow. $\mathrm{SiC}$ power devices tend to show better performance when it is used as n-channels rather than p-channels; to achieve even more enhanced performance, the device needs to be grown epitaxially on low-resistivity p-type substrates. However, at present, the commercially available p-type $4 \mathrm{H}-\mathrm{SiC}$ substrate has relatively high resistivity $(\sim 2.5 \Omega \cdot \mathrm{cm})$, which is about two orders of magnitude higher than that of the $\mathrm{n}$-type substrate [96]. The advantages of $\mathrm{n}$-channel $\mathrm{SiC}$ devices weaken if the high resistivity p-type substrate is used. Hence, due to the present issue of the nonavailability of p-type substrates with low resistivity, reverse growth is studied by growing layers on commercial $n+$ substrates to enhance the performance [97].

To further improve the performance of the device, the trench design process of the device is also considered. The trench structure has been widely used in Si-MOSFETs, and it has also attracted much attention in SiC-MOSFETs. Trench SiC MOSFET exhibited no degradation in both the on-resistance of differential body diodes and the on-resistance 
of the device even after continuous current stress of $500 \mathrm{~h}$ [98]. Moreover, the trench $\mathrm{SiC}$ MOSFET exhibits lower on-resistance than the conventional design as the trench design does not have JFET regions [99].

In the fabrication process steps of the trench MOSFET, the implantation of the pbase step and the trench formation step can be interchanged, i.e., by performing $p$ base implantation first and then making trench structure, as in [100], or making the trench first and then the p-base implantation, as in [101]. The fabrication process flow by performing trench first is shown in Figure 5. The process step is as follows: first, the $\mathrm{n}$ - drift region is epitaxially grown on $\mathrm{n}+$ substrate; then, the trenched gate region, after the structure is trenched by implantation by using $\mathrm{Al}$ or $\mathrm{N}$, is done to make the $\mathrm{p}$-base region; subsequently, $\mathrm{p}+$ implantation is done to form the shielding region, and then $\mathrm{n}+$ implantation is performed for defining the source and drain regions. After the implantation steps, the resulted structure is then exposed to high temperatures for thermal oxidation to form gate oxide after annealing, and then the gate electrode, source metal, and drain metal are deposited. Finally, the structure is coated with a polyimide layer as a protective passivation layer. To improve the performance of the device by reducing the number of defects present in the $\mathrm{SiC}$ substrate and epitaxial layer, various methods of ion implantations and thermal oxidation processes are employed [96,97].

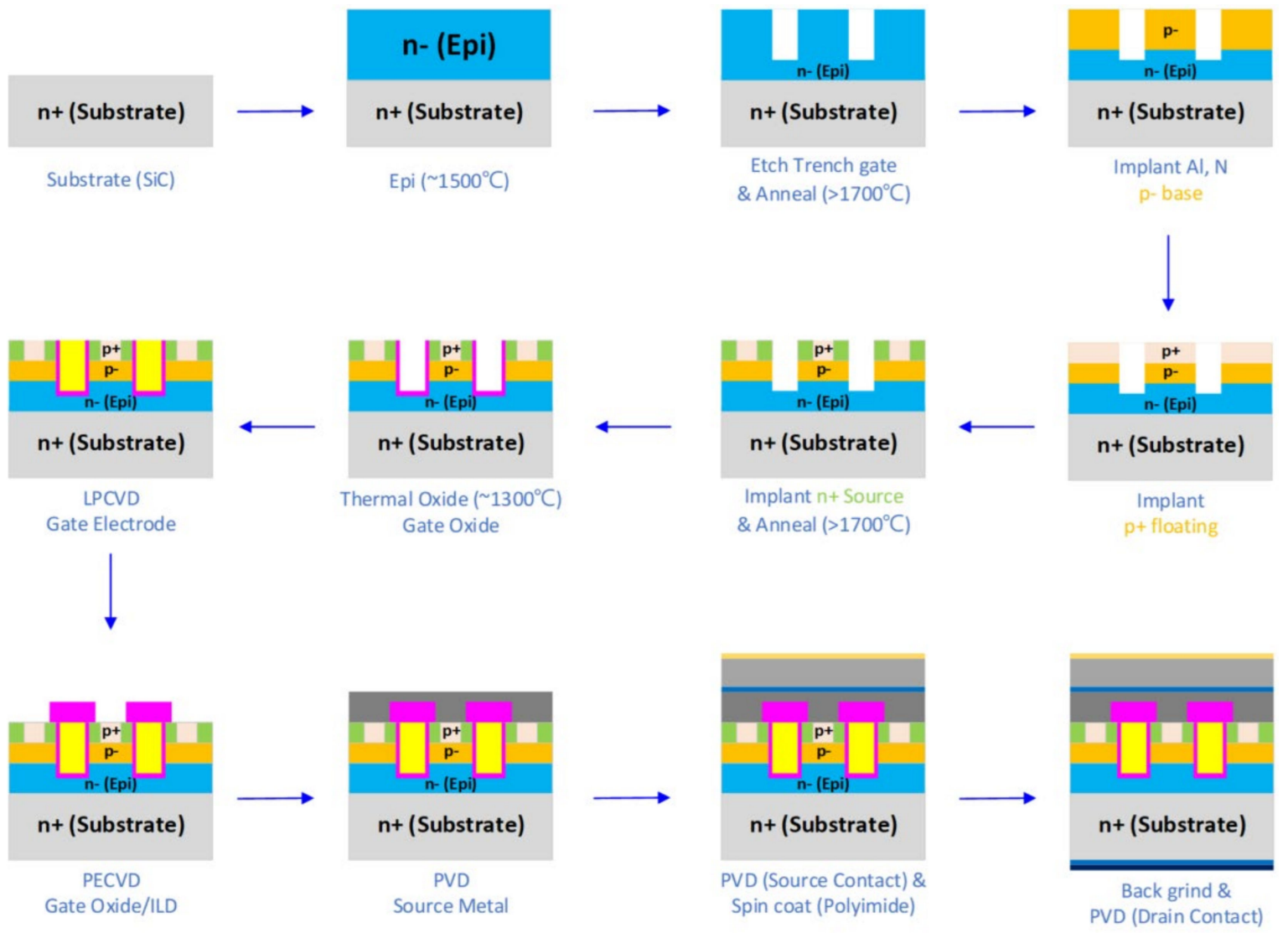

Figure 5. SiC MOSFET process flow.

The performance, reliability, and stability of the $\mathrm{SiC}$ devices also depend on the quality of the $\mathrm{SiC}$ wafers [102,103], and the yield of the $\mathrm{SiC}$ components indirectly affects the cost of manufacturing. The total defects of $\mathrm{SiC}$ wafers are mainly intrinsic material defects and structural defects caused by epitaxial growth. These defects act as recombination centers and reduce the carrier lifetime of the thick drift region significantly. Different optimization process parameters, such as C+ ion implantation/annealing, thermal oxidation/annealing, or trench design, could reduce these defects to a very low level of about $10^{11} \mathrm{~cm}^{-3}$ [104]. 
To reduce the interface trap density for further improving the device performances, a thin insulator with a high dielectric constant and a large bandgap was deposited by atomic layer deposition (ALD) technology [105-109]. Several ALD materials such as $\mathrm{Al}_{2} \mathrm{O}_{3}, \mathrm{AlN}$, and $\mathrm{ZrO}_{2}$ have also exhibited the ability to improve the properties of power electronic components significantly [110-112]. However, although many efforts have been made to reduce these defects, they still exist and greatly affect the carrier lifetime. In addition, the trade-off between target defects and new defects caused by post-growth and the contradiction between C-plane and Si-plane epitaxial growth further hinder its commercialization. Therefore, the supply of large-size and high-quality materials and the epitaxial growth process with low defect density are the keys to the commercialization of $\mathrm{SiC}$ devices.

\subsection{SiC Substrate}

The semiconductor $\mathrm{SiC}$ is widely known for its appearance in various stable crystal polytypes. The crystal structure differs from the different stacking order to the Si-C double layer, where each $\mathrm{Si}$ is surrounded by four $\mathrm{C}$ atoms, as shown in Figure 1. Physically, it is mainly a large bandgap and good thermal conductivity material, as shown in Table 1. A general growth process of $\mathrm{SiC}$ is done by the physical vapor transport (PVT) method. The sketch of a typical PVT growth method is shown in Figure 6a [113]. The SiC source is placed on the graphite crucible, and the apparatus is surrounded by insulation materials. The temperature field is mainly determined by the crucible and the surrounding isolation parts, which are in the case of a long coil. The growth method is done at a high temperature of about $2000{ }^{\circ} \mathrm{C}$ or more. It shows as a feasible design to susceptor of the electromagnet heating power and inductive heating in PVT growth technology. It reaches a low background doping level in a high vacuum range of $10^{-6}$ to $10^{-7}$ mbar.

a)

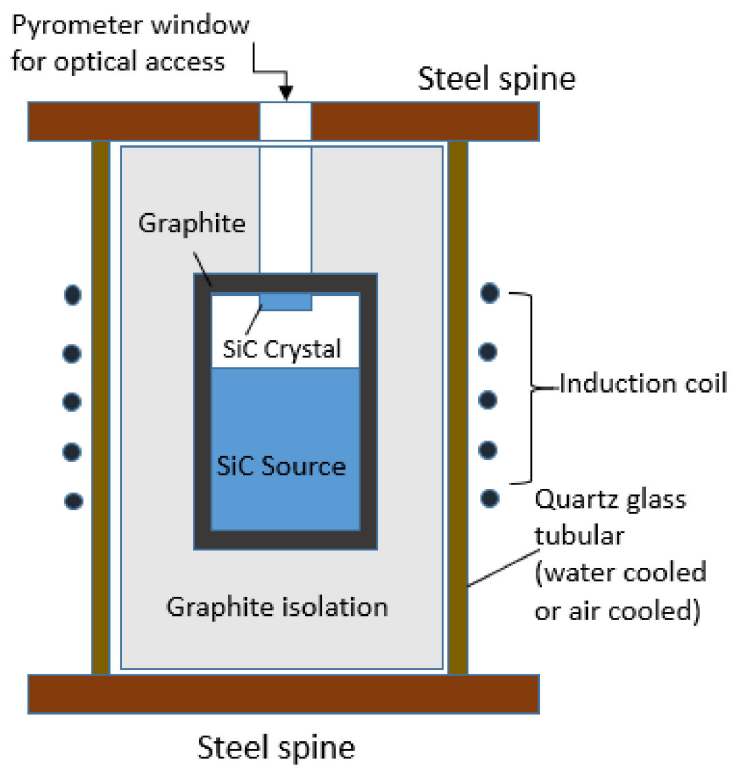

b)

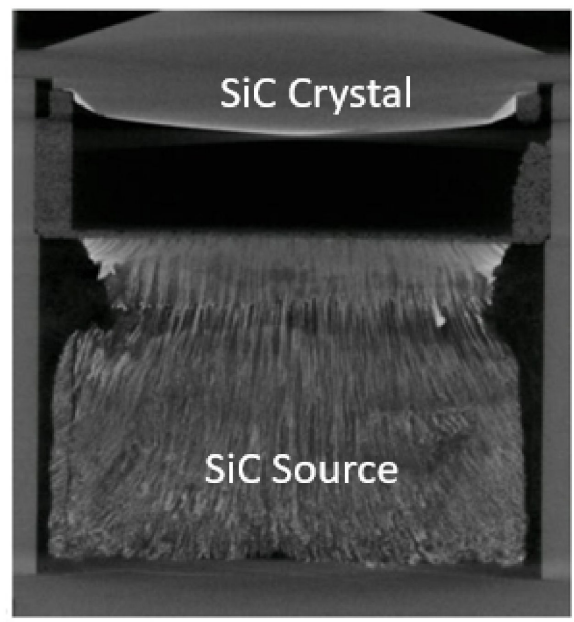

Figure 6. (a) A sketch of the PVT growth method for SiC boules and (b) 2D visualization of the PVT growth to image the great details about the morphology and the crystal growth interface and conditions [113].

The X-ray imaging in 2D [114-116] and 3D illustrations [117,118] are shown in Figures $6 \mathrm{~b}$ and 7. This application indicates that the in-situ visualization of the PVT growth process is available. Employing the in-situ X-ray diffraction to analyze the visualization of polymorphic transformation [119] and the curvature of the lattice plane [113] have been demonstrated during the crystal growth. 

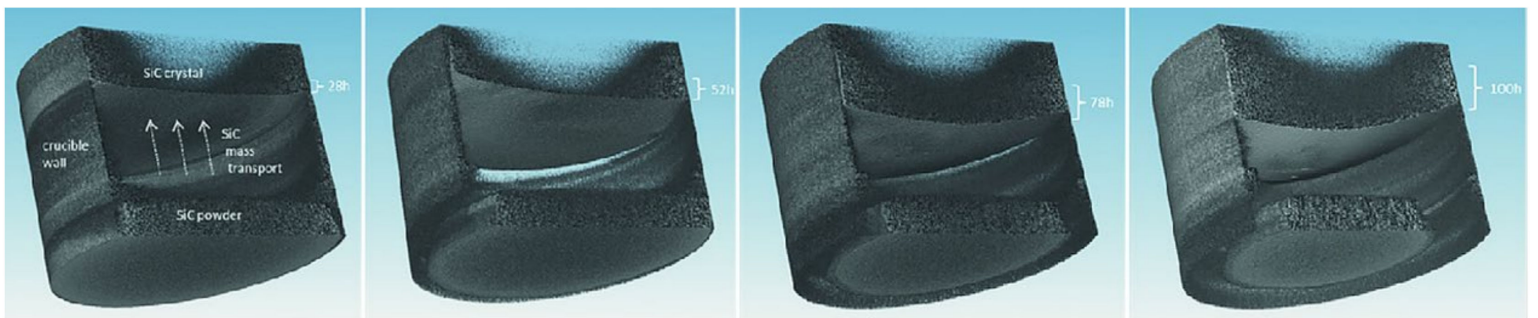

Figure 7. 3D in situ x-ray visualization of the PVT growth process using computed tomography: detailed visualization of the crystal's growth interface [113].

Furthermore, a wafering process includes grinding the crystal to a specific size and fabricating a flat plane in the direction of the substrate. The multiple-wire saw is usually used for wafer dicing. A stainless-steel wire and diamond-based slurry are used for abrasive materials. On the other hand, diamond-coated steel wire and laser cutting are also available in new wafering technologies. However, the new technologies require further technological development. To achieve a smooth and mirror-like wafer surface, three process steps are required, such as (1) grinding the diced wafer, (2) polishing with diamond slurry to obtain an optically perfect surface, and (3) chemical mechanical polishing (CMP) to fabricate a wafer-level SiC substrate for the next power device process.

\subsection{SiC Epitaxy}

Homoepitaxial growth was researched on commercially $4^{\circ}$ off-axis $4 \mathrm{H}-\mathrm{SiC}(0001)$ Si-face substrates using a horizontal hot-wall chemical vapor deposition reactor; its reactive source included $\mathrm{SiH}_{4}, \mathrm{C}_{3} \mathrm{H}_{8}$, and $\mathrm{H}_{2}$ [120]. First, $\mathrm{H}_{2}$ etching in the epitaxial chamber was generally done at $1650{ }^{\circ} \mathrm{C}$ for $25 \sim 35 \mathrm{~min}$ before the $\mathrm{SiC}$ epitaxy. The pressure during $\mathrm{H}_{2}$ etching was around $3.5-5.5 \mathrm{kPa}$. Typical growth was at $1600-1650{ }^{\circ} \mathrm{C}$, and the $\mathrm{SiH}_{4}$ flow rate was varied from 1 to $30 \mathrm{sccm}$ in $\mathrm{H}_{2}$ carrier gas flow at a fixed rate of $10 \mathrm{slm}$. Figure 8a shows the $\mathrm{SiH}_{4}$-flow-rate dependence on the growth rate at a moderate $\mathrm{C} / \mathrm{Si}$ ratio $(\mathrm{C} / \mathrm{Si}=1.2)$ in source gases $[121,122]$. The growth rate increased through the $\mathrm{SiH}_{4}$ flow rate, and it reached $85 \mu \mathrm{m} / \mathrm{h}$ at a $\mathrm{SiH}_{4}$ flow rate of $30 \mathrm{sccm}$. Figure $8 \mathrm{~b}$ shows a smooth surface in $150 \mathrm{~mm}$-diameter $4 \mathrm{H}-\mathrm{SiC}$ epitaxy at a $77 \mu \mathrm{m} / \mathrm{h}$ growth rate [123].

a)

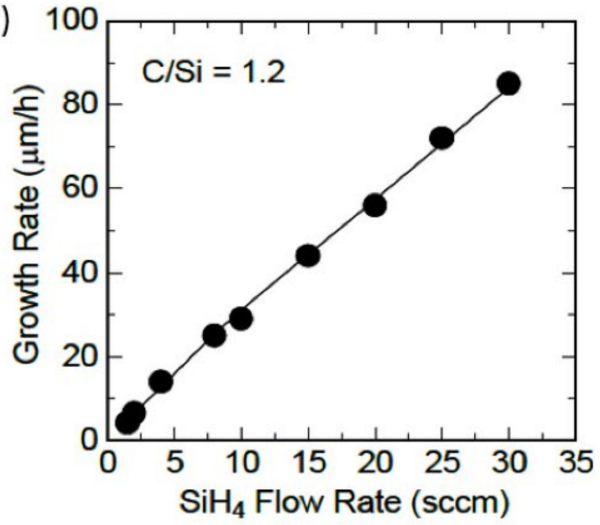

b)

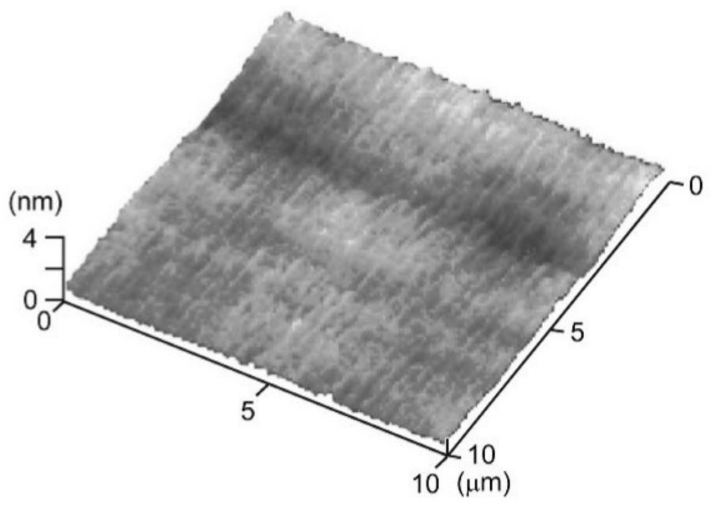

Figure 8. (a) $\mathrm{SiH}_{4}$-flow-rate dependence of the growth rate at a $\mathrm{C} / \mathrm{Si}$ ratio $(\mathrm{C} / \mathrm{Si}=1.2)$ in the homoepitaxial growth of $4 \mathrm{H}-\mathrm{SiC}(0001)$ [121,122]. (b) AFM results from a $150 \mathrm{~mm}$-diameter $4 \mathrm{H}-\mathrm{SiC}$ epitaxy grown at $77 \mu \mathrm{m} / \mathrm{h}[123]$.

Furthermore, both $\mathrm{SiH}_{4}$ and $\mathrm{C}_{3} \mathrm{H}_{8}$ flow rates increase with a moderate or high $\mathrm{C} / \mathrm{Si}$ ratio, and the doping concentration will decrease. In comparison, the amount of excess carbon increases with the total source gas flow rate, and the epitaxial growth rate increases on the growing surface $[121,122]$. It induces suppression of nitrogen incorporation at high flow rates of $\mathrm{SiH}_{4}$ and $\mathrm{C}_{3} \mathrm{H}_{8}$, and the effect results from the increase in effective $\mathrm{C} / \mathrm{Si}$ ratios [124]. It shows a good epitaxial surface that almost exhibits the less disordered 
bunching in growth processes, which also reaches the RMS roughness of $0.21 \mathrm{~nm}$ in Figure $8 \mathrm{~b}$ [123]. Therefore, the bigger $\mathrm{C} / \mathrm{Si}$ ratio also brings surface roughness and impacts p-type conductivity. However, it is usually made in the 3C-triangular defects and various SFs confirmed in $4 \mathrm{H}-\mathrm{SiC}$ epilayers. The different types of SFs could be identified as different formation mechanisms, as illustrated in Figure 9 [123].

a)

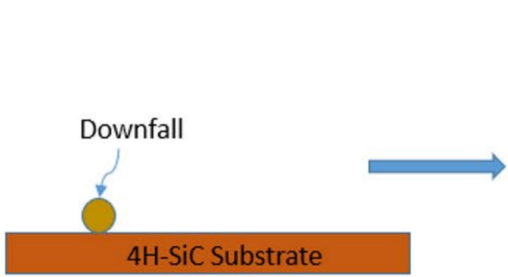

b)

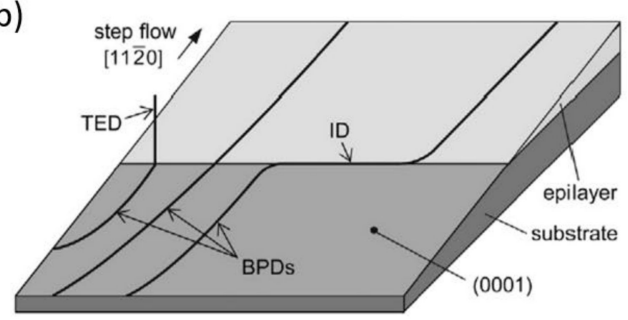

Figure 9. (a) Schematic illustration of the formation of downfall and (b) 3C-triangular defects and BPD propagation in $4 \mathrm{H}-\mathrm{SiC}$ epitaxial growth [123].

\subsection{Ion Implant}

Ion implantation is an important process for manufacturing almost all types of $\mathrm{SiC}$ devices. A wide range of doping control of n-type and p-type conductivity can be achieved by ion implantation. Since the diffusion coefficient of the dopants in $\mathrm{SiC}$ is very small, most of the diffused impurities during implantation can be ignored during the post-implantation annealing process. However, if the damage to the crystal lattice during implantation is close to the amorphous state, it is difficult to restore the crystal lattice. Therefore, high temperature $\left(\sim 500^{\circ} \mathrm{C}\right)$ implantation is usually used, especially when the implant dose is very high. Additionally, it is necessary to perform post-implantation annealing at a very high temperature $\left(>1700^{\circ} \mathrm{C}\right)$ to achieve lattice recovery and a high electrical activation rate. This high-temperature annealing may cause inconsistent silicon evaporation and a rough surface. Figure 10a shows the dependence of the electrical activation rate on the annealing temperature of $\mathrm{SiC}$ implanted with nitrogen $(\mathrm{N})$ or phosphorus $(\mathrm{P})$; the implantation is done at room temperature (RT) [125]. The activation rate below the annealing temperature of $1300^{\circ} \mathrm{C}$ is very small $(<10 \%)$, and high-temperature annealing at $1600 \sim 1700^{\circ} \mathrm{C}$ is required to obtain a nearly perfect activation rate $(>95 \%)$.

a)

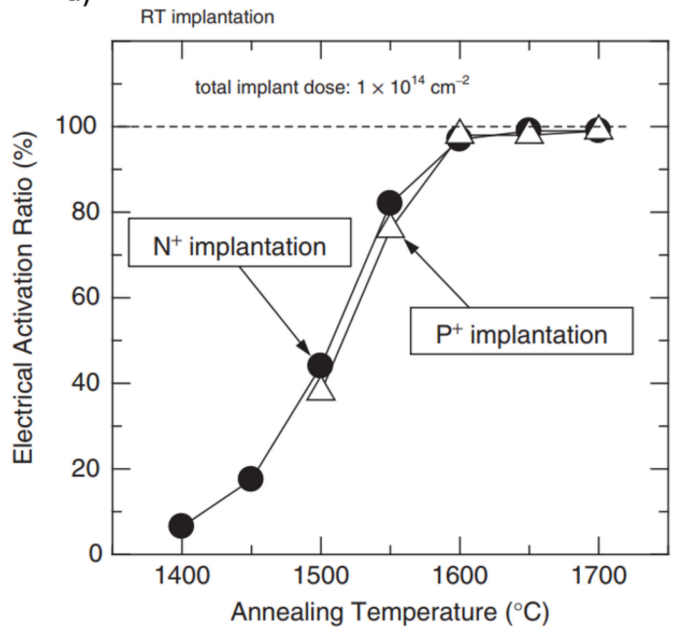

b)

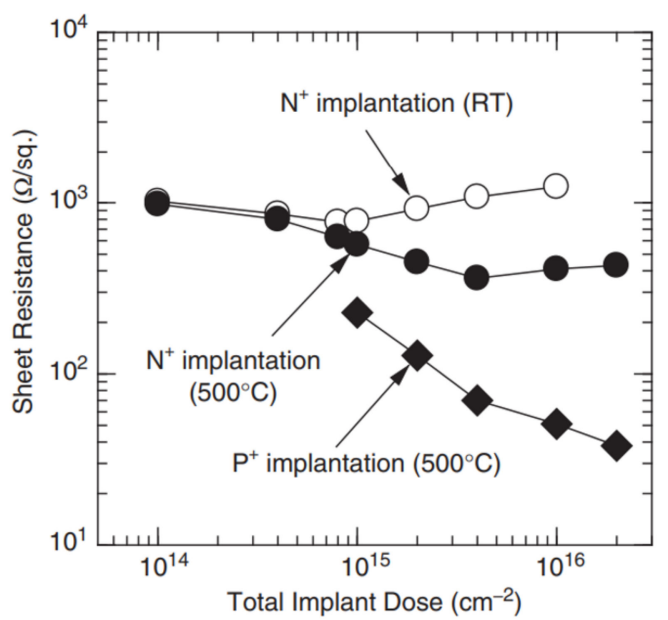

Figure 10. (a) Annealing-temperature dependence of the electrical activation ratio in nitrogen- (N) or phosphorus (P)-implanted SiC. (b) Sheet resistance versus the total implant dose for N- or Pimplanted $\mathrm{SiC}$ annealed at $1700{ }^{\circ} \mathrm{C}$ for $30 \mathrm{~min}$ [125]. Copyright (C) $2022 \mathrm{John}$ Wiley \& Sons, Singapore Pte. Ltd. 
Figure $10 \mathrm{~b}$ shows the relationship between the sheet resistance of $\mathrm{N}$ - or P-implanted $\mathrm{SiC}$ annealed at $1700^{\circ} \mathrm{C}$ for $30 \mathrm{~min}$ and the total implant dose. When the implant dose is relatively low $\left(<3 \times 10^{14} \mathrm{~cm}^{-2}\right)$, there is no significant difference in the sheet resistance of the $\mathrm{N}+$ implant type, regardless of the implant temperature (RT or $500{ }^{\circ} \mathrm{C}$ ) [125]. In the case of RT implantation, the sheet resistance at the implant dose is about $0.7-1 \times 10^{15} \mathrm{~cm}^{-2}$, and it increases with the further increase of the implant dose. In this high-dose region, the lattice damage caused by room temperature implantation is very serious. After activation annealing, the implanted area contains high-density stacking faults and 3C-SiC crystal grains. On the other hand, it was observed that the sheet resistance decreases as the thermal implantation dose increases. The maximum sheet resistance of the nitrogen-implanted area is almost saturated at $300 \Omega$ /sq., which may be limited by the relatively low solubility of $\mathrm{N}$ atoms in $\mathrm{SiC}$. The sheet resistance can be further reduced to $30-50 \Omega / \mathrm{sq}$ by thermally injecting $\mathrm{P}$. This process is possible due to the higher solubility limit of $\mathrm{P}$.

\subsection{Oxidation}

Like $\mathrm{Si}, \mathrm{SiC}$ also has the ability to produce high-quality $\mathrm{SiO}_{2}$ through thermal oxidation. Hence, to form gate dielectric, thermal oxidation is performed on SiC. However, the presence of carbon atoms in $\mathrm{SiC}$ exhibits a significant difference to that of the oxide quality achieved from Si technology [126]. Although the interface of oxide and the epilayer of SiC MOSFET continues to improve, the quality and the understanding of the factors that control the quality is still far from a satisfactory level. The behavior of SiC power MOSFETs mainly depends on the characteristics of the $\mathrm{SiO}_{2} / 4 \mathrm{H}-\mathrm{SiC}$ MOS system, i.e., the amount of slow near-interface oxide traps (NIOTs) present inside the oxide layer, bulk traps, interface state density $\left(\mathrm{D}_{\mathrm{it}}\right)$ distribution, and the modification of the $4 \mathrm{H}-\mathrm{SiC}$ area near the $\mathrm{SiO}_{2}$ interface by MOS systems. The brief location of NIOTs and $D_{i t}$ is shown in Figure 11 [127]. $D_{\text {it }}$ is present near the edge of the valence band or conduction band at the $\mathrm{SiO} 2 / 4 \mathrm{H}-\mathrm{SiC}$ interface, and NIOTs are present inside the gate insulator.

\section{Metal $\mathrm{SiO}_{2} \quad 4 \mathrm{H}-\mathrm{SiC}$}

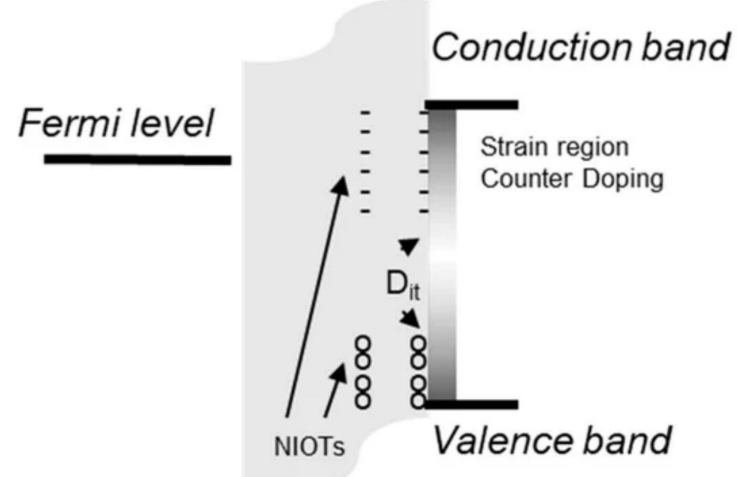

Figure 11. Graphical representation of the location of oxide traps and interface traps present at the interface of $\mathrm{SiO} 2 / 4 \mathrm{H}-\mathrm{SiC}[127]$.

The other important problem of SiC-MOS devices is the poor reliability of the gate oxide layer, such as the low dielectric breakdown field and threshold voltage instability. However, due to the recent advancement in technology and equipment, different $\mathrm{SiO}_{2}$ passivation processes can be used to improve the trench mobility of the gate oxide layer of $\mathrm{SiC}$ devices. The passivation process can be achieved by thermal annealing in a chamber filled with nitrogen $\left(\mathrm{N}_{2} \mathrm{O}\right.$ or $\left.\mathrm{NO}\right)[128,129]$. The comparison of measured doping concentration and the $\mathrm{D}_{\text {it }}$ of various nitrogen-based annealing processes, based on some literature on $4 \mathrm{H}-\mathrm{SiC}$ devices, is shown in Table 2 [130-134]. These data were fabricated on epitaxial layers or ion-implanted layers or MOS capacitors under nitrogen-filled conditions. Most of the annealing temperature of the passivation layer falls within the range of $1100-1400{ }^{\circ} \mathrm{C}$. 
Table 2. Summary of p-type doping concentration and interface state density (Dit) data of gate oxide in $4 \mathrm{H}-\mathrm{SiC}$ devices.

\begin{tabular}{ccccc}
\hline Process & Temperature $\left({ }^{\circ} \mathbf{C}\right)$ & $\mathbf{N}_{\mathbf{A}}\left(\mathbf{c m}^{-3}\right)$ & $\mathbf{D}_{\mathbf{i t}}\left(\mathbf{c m}^{-\mathbf{2}} \mathbf{e V} \mathbf{- 1}\right)$ & Ref. \\
\hline $\mathrm{NO}$ & 1250 & $1.3 \times 10^{15}$ & $2 \times 10^{14}$ & {$[130]$} \\
\hline $\mathrm{NO}$ & 1250 & $2.3 \times 10^{15}$ & $8 \times 10^{13}$ & {$[130]$} \\
\hline $\mathrm{NO}$ & 1250 & $2.7 \times 10^{15}$ & $6 \times 10^{13}$ & {$[130]$} \\
\hline $\mathrm{NO}$ & 1175 & $8 \times 10^{15} \mathrm{epi}$ & $\mathrm{N} . \mathrm{A}$. & {$[131]$} \\
\hline $\mathrm{N}_{2} \mathrm{O}$ & 1150 & $10^{17} \mathrm{imp}$ & $3.6-7.2 \times 10^{11}$ & {$[132]$} \\
\hline $\mathrm{N}_{2} \mathrm{O}$ & 1300 & $1 \times 10^{16} \mathrm{epi}$ & $4 \times 10^{11}$ & {$[133]$} \\
\hline $\mathrm{N}_{2} \mathrm{O}$ & 1410 & $5 \times 10^{15}$ epi & $10^{12}$ & {$[134]$} \\
\hline
\end{tabular}

\section{SiC MOSFETs}

Since the beginning, MOSFETs have been the most successful devices and are mainly employed for switching operations in power converters [135]. The structure of $\mathrm{SiC}$ power MOSFETs is similar to that of Si MOSFETs with an insulated gate structure. SiC power MOSFETs can operate over a wide range of blocking voltage, with lower conduction and switching loss, as the device has less on-resistance than the Si counterpart and is much smaller [136]. The main advantage of $\mathrm{SiC}$ power MOSFETs is that the SiC power MOSFET combines the excellent material properties of $\mathrm{SiC}$, which enhances the performance of the device. However, the $\mathrm{SiC}$ power MOSFET suffers from the carbon cluster introduction at the gate oxygen interface, which increases $D_{i t}$ at the gate-oxide interface, and thus, the channel resistance increases.

$\mathrm{SiC}$ Power MOSFETs are classified into different types depending on the structural modification of the gate and the drift region. The classification of the device is illustrated in Table 3. The two basic types of SiC MOSFET structures based on the gate modification are planar MOSFETs (DMOSFETs) and trench MOSFETs (UMOSFETs) [99], as shown in images (a) and (b) in Table 3, respectively. The planar types are further classified into conventional and super junction MOSFETs (SJ MOSFETs), as shown in image (c) in Table 3. A detailed discussion on the types of $\mathrm{SiC}$ MOSFETs can be found in the following sections.

\subsection{Planar and Trench MOSFETs}

The planar MOSFETs (or DMOSFETs), as shown in image (a) in Table 3, are a double diffusion MOS structure where the channel is formed by a double diffusion process and has the ability to withstand high voltage [137]. However, the performance of the device is affected by the poor channel mobility due to the scattering process at the interface of the $4 \mathrm{H}-\mathrm{SiC} /$ insulator. This scattering causes a significant reduction in mobility at the interface when compared with that of the bulk. Moreover, the presence of parasitic junction FET resistance increases the conduction loss during the forward condition [138]. A 4H-SiC Planar MOSFET with a blocking voltage of $2.3 \mathrm{kV}$ was proposed in [139]. The device has an acceptable gate oxide electric field with a gate oxide thickness of $27 \mathrm{~nm}$. The device was fabricated using a commercial foundry. The device exhibits an improvement in $R_{o n}$, sp, and a high-frequency figure of merit (FOM) by 1.3 times when a $15 \mathrm{~V}$ is applied at the gate. However, the device suffers from gate voltage overshoot failure due to the thin gate oxide. A $4 \mathrm{H}-\mathrm{SiC}$ Planar MOSFET with multiple floating guard-rings for edges termination was developed; the device can achieve a blocking voltage of $2.4 \mathrm{kV}$ and a specific on-resistance of about $42 \mathrm{~m} \Omega \mathrm{cm}^{2}$ [140]. The fabricated device exhibits a mobility of $22 \mathrm{~cm}^{2} /$ V.s in the channel and has a threshold voltage of about $8.5 \mathrm{~V}$. 
Table 3. Basic classification of SiC MOSFETs based on gate and drift structure.

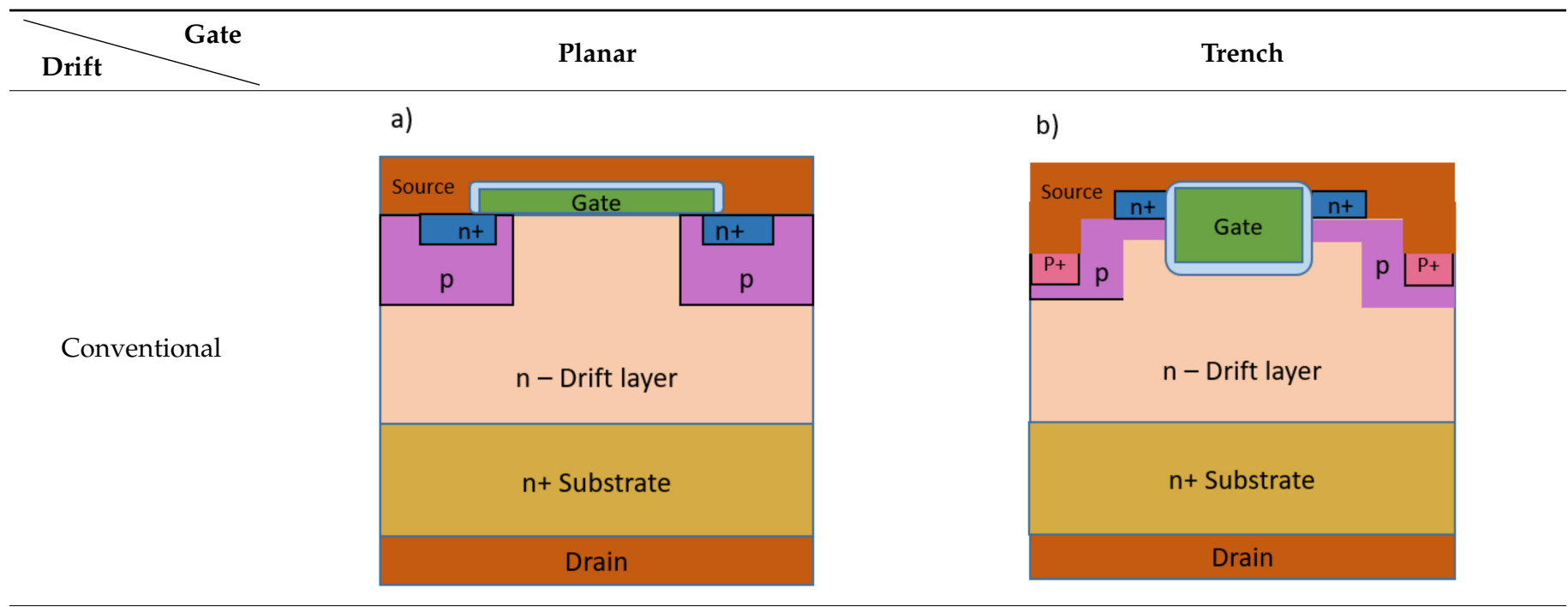

c)

Superjunction

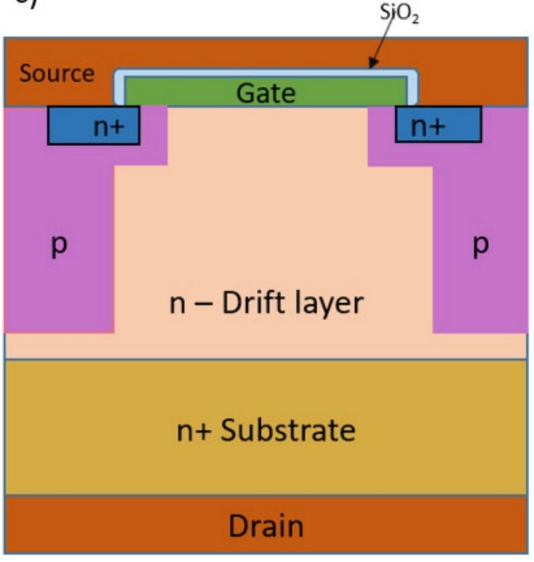

To minimize the conduction and switching loss in the planar MOSFET, the trench MOSFET or UMOSFET was developed for power application. The structure of trench MOSFET is shown in image (b) in Table 3; it has a vertical gate channel in U groove shape and a channel form at the sidewalls of the trench. This structure improved the channel migration rate and was able to eliminate the parasitic JFET resistance [141]. In addition, the on-resistance of the trench $\mathrm{SiC}$ MOSFET is half the planar SiC MOSFET. Hence, the trench $\mathrm{SiC}$ MOSFET design is preferred for power devices [98,142].

The first trench MOSFET was first introduced in 1992 by Palmour et al. [143]. In 1994, a trench MOSFET with a breakdown voltage of $150 \mathrm{~V}$ and $R_{\mathrm{on} \text {, sp }}$ of about $3.3 \mathrm{~m} \Omega \mathrm{cm}^{2}$ was demonstrated [144]. However, the device suffers from low mobility in the inversion layer due to the presence of a high electric field at the trench corner in the oxide, which restricts the breakdown voltage of the device. A $1.2 \mathrm{kV}$ trench gate SiC MOSFET with a low switching loss was developed by Fiji Electric [145]. The proposed device exhibits a $48 \%$ reduction in on-resistance, with a higher threshold voltage than the conventional $\mathrm{SiC}$ planar MOSFET. A $4 \mathrm{H}-\mathrm{SiC}$ Planar MOSFET with a blocking voltage of $2.3 \mathrm{kV}$ was proposed [139]. The device has an acceptable gate oxide electric field, with a gate oxide thickness of $27 \mathrm{~nm}$. The device was fabricated using a commercial foundry. The device exhibits an improvement in the specific on-resistance and high-frequency figure of merit by 1.3 times when the applied gate bias is $15 \mathrm{~V}$. However, the device suffers from gate voltage overshoot failure due to the thinner gate oxide. 
A 4H-SiC Planar MOSFET with multiple floating guard-rings for terminating the edges was developed; the device can achieve a blocking voltage of $2.4 \mathrm{kV}$ and a specific onresistance of about $42 \mathrm{~m} \Omega \mathrm{cm}^{2}$ [140]. The fabricated device exhibits a mobility of $22 \mathrm{~cm}^{2} /$ V.s in the channel and has an $8.5 \mathrm{~V}$ threshold voltage. Purdue University introduced a trench MOSFET with a blocking voltage of $5 \mathrm{kV}$, with protection in the trench oxide and an extension in the junction termination $[140,146]$. A $4 \mathrm{H}-\mathrm{SiC}$ planar MOSFET with the highest blocking voltage of about $10 \mathrm{kV}$ was reported in [147].

The major issue of the common single trench is the concentration of the electric field at the bottom of the gate trench, which imposes a reliability issue to the device under long-term use. Additionally, it also suffers from the degradation of the switching performance and also the degradation of breakdown voltage due to the high value of gate-drain capacitance. To overcome the immature breakdown and reliability problem of the oxide, a double trench SiC MOSFET (DT MOS) was developed; it distributes the electric field concentration on the gate oxide into the source region $[99,148,149]$. The structure has a $p+$ shielding region to distribute the high gate oxide electric field to the source and drain $\mathrm{p}+$ regions, which help in improving the breakdown voltage of the device [150]. The $p+$ shielding also improves the switching performance of the device by reducing the gate and drain charge coupling effect [151].

For high power switching applications, to increase the switching speed with lesser switching losses, a smaller value of reverse transfer capacitance $\left(\mathrm{C}_{\mathrm{GD}}\right)$ and lower gatedrain charge $\left(\mathrm{Q}_{\mathrm{GD}}\right)$ is necessary. A split-gate double trench MOSFET (SG-MOSFET) was proposed, with a better high-frequency FOM $\left(R_{\mathrm{on}, \mathrm{sp}} \times \mathrm{Q}_{\mathrm{GD}}\right)$ than the DT MOS $[152,153]$. The structure has a separate upper and lower gate terminal; the upper gate terminal is connected to the gate voltage and is lower than the source voltage. The area under the active channel is reduced, which enhances the switching performance by reducing the gate-drain capacitance. Central implant MOSFET (CI MOSFET) is another type of structure demonstrated by Wolfspeed; it exhibits lower $\mathrm{C}_{\mathrm{GD}}$ and $\mathrm{Q}_{\mathrm{GD}}$ [154]. In power inverter applications, to reduce the $\mathrm{SiC}$ Chip area, $\mathrm{SiC}$ MOSFETs are used with free-wheeling diodes (FWD), namely, parasitic body PiN diodes. However, these diodes result in bipolar degradation and increase on-state power dissipation [155]. To overcome these issues, a different variety of embedded parallel Schottky barrier diodes (SBDs) with SiC MOSFETs has been proposed [156-162].

\subsection{Superjunction MOSFETs}

Superjunction (SJ) is a technique utilized widely to overcome the $\mathrm{R}_{\mathrm{on} \text {, sp }} \mathrm{xA}$ limitation in Si devices [163]. A superjunction MOSFET (SJ MOSFET) structure has alternating $p$ and $\mathrm{n}$ layers in the drift region, as shown in image (c) in Table 3. The structure is formed by penetrating $\mathrm{p}+$ columns into the n-epitaxial layer and follows the charge compensation principle, which helps in distributing the electric field uniformly inside the drift region [164]. As a result, the performance of the SJ MOSFET surpasses the conventional MOSFET performance. The main benefit of SJ MOSFETs is the linear relationship between $R_{o n}$, sp and the breakdown voltage (BV) [165], whereas for conventional MOSFETs (planar), the

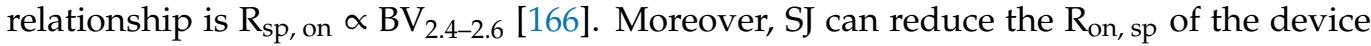
without compromising the BV voltage of the device [163].

The structure of SJ MOSFETs can be grown by trench filling or by multi epitaxial growth. The epitaxial growth of SJ by trench filling is shown in Figure 12a and by multi epitaxial growth in Figure 12b. The trench filling epitaxial growth process is done by dry etching at the beginning to form a deep trench, and then, on the trench surface, an epitaxial layer is grown in the trench $[167,168]$. The multi-epitaxial growth method is a fabrication method that is used to achieve a certain thickness of drift-layer by combining epitaxial growth and the ion implantation method of fabrication [166]. The fabrication process of the SJ structure was first introduced by R. Kosugi et al. [169]. The measured breakdown voltage and $R_{o n}$, sp of the fabricated pn-pillar structure were $1545 \mathrm{~V}$ and $1.06 \mathrm{~m} \Omega \mathrm{cm}^{2}$, respectively; the structure has a $5.5-\mu \mathrm{m}$-thick pn-pillar structure, grown using multiple 
epitaxial growth method. The breakdown voltage and specific on-resistance achieved are almost the same as that of the theoretical limit of SiC. In addition, SiC-based SJ structures have been exhibited to show a reduction in on-resistance by 140 times and have a smaller pillar charge imbalance effect than the Si SJ structures [170].

a)

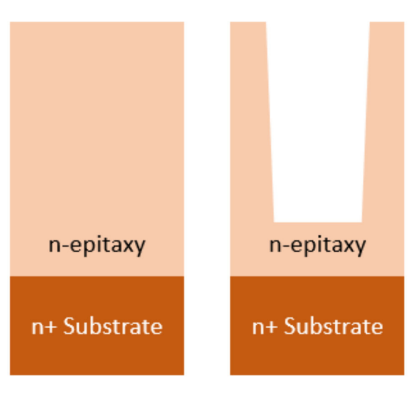

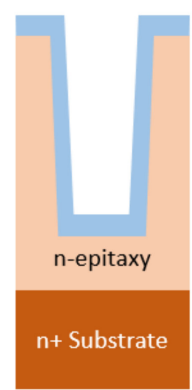

b)

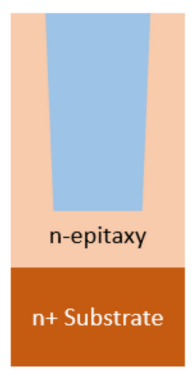

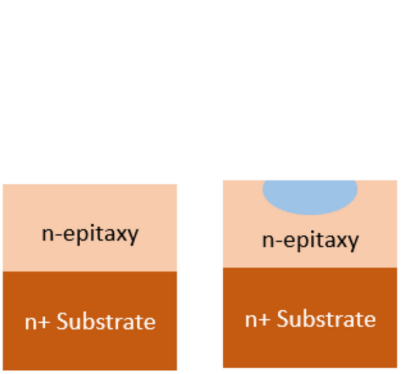

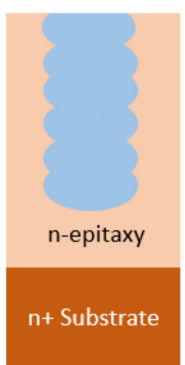

Figure 12. (a) Trench-filling epitaxial growth and (b) multi-epitaxial growth.

SiC SJ MOSFETs have also exhibited an excellent Baliga's figure of merit (FOM) $\left(\mathrm{BV}^{2} / \mathrm{R}_{\mathrm{on}, \mathrm{sp}}\right)$ when compared with other $\mathrm{SiC}$ devices [171]. Simple analytical models for predicting the on-resistance and breakdown voltage of SiC SJ MOSFETs were proposed in $[172,173]$. Furthermore, SiC SJ MOSFETs exhibited a lower charge imbalance effect when compared with Si SJ MOSFETs in the drift region [170]. To achieve a better trade-off between the $\mathrm{BV}$ and $\mathrm{R}_{\mathrm{on}, \mathrm{sp}}$, many researchers aimed to obtain the desired result by modifying the doping profile or the structure of the device. A SiC SJ MOSFET with a variation in the vertical doping profile (VVD) was proposed [164]; the device exhibits a better trade-off between the on-resistance and BV. The proposed device also shows the best results in both Baliga's and conventional FOM. A SiC SJ V-groove trench MOSFET with a breakdown voltage of $820 \mathrm{~V}$ and an on-resistance of $0.97 \mathrm{~m} \Omega \mathrm{cm}^{2}$ was reported by Masuda et al. [174]. A SiC SJ V-groove trench MOSFET with a smaller on-resistance of $0.63 \mathrm{~m} \Omega \mathrm{cm}^{2}$ and a breakdown voltage of $1170 \mathrm{~V}$ was demonstrated in [73]. The proposed device has a lower on-resistance than the SiC MOSFETs with a breakdown voltage of over $600 \mathrm{~V}$.

A class of $1.2 \mathrm{kV}$ SiC SJ MOSFETs, with an extremely low value of $R_{o n}$, sp $x A$, a higher value of withstanding the short-circuit capability, and a significantly lower value of reverse recovery loss, was demonstrated in [73,175-177]. A DC-FSJ MOSFET (different concentration floating super junction MOSFET) was proposed [178], and the device was able to achieve a breakdown voltage of more than $3.3 \mathrm{kV}$, along with reduced $R_{\text {on, sp. The }} R_{\text {on, sp }}$ of the proposed structure was $25 \%$ less than conventional vertical MOSFET under the same conditions. The structure was fabricated by implementing multiple epitaxial growths with floating p-type structures and different concentrations of epitaxial layers. The BFOM of the device increased by $18 \%$ from FSJ MOSFETs and by $27 \%$ from vertical MOSFETs. A SiC SJ MOSFET with a very high breakdown voltage of $3.3 \mathrm{kV}$ and a low $R_{\text {on, sp }}$ of $3.3 \mathrm{~m} \Omega \mathrm{cm}^{2}$ at $27{ }^{\circ} \mathrm{C}$ and $6.2 \mathrm{~m} \Omega \mathrm{cm}^{2}$ at $175{ }^{\circ} \mathrm{C}$ was developed in [179]. The proposed devices were able to exceed the theoretical limit of the unipolar $\mathrm{SiC}$ device.

Although $\mathrm{SiC}$ power devices have come a long way in improving their performances and satisfying the increasing demands, it is noteworthy to mention one of the key technical challenges faced, i.e., the reduction of electric field on the surface or at the edges of the device. The reduction of the electric field becomes more challenging with device miniaturization. Some in-plane edge termination techniques have been demonstrated for SiC power devices, which have a similar concept to that of Si power devices. The techniques include field plates [180,181], mesa structures [182], junction termination expansion (JTE) [183-185], floating field rings (FFR) [186,187], ramp structures [188,189], ion implantation, and hybrid solutions [37,190-193]. Edge terminations are generally used at the device periphery so that it supports the maximum amount of the bulk breakdown value [194]. Hence, robust and reliable edge terminations are one of the most important requirements that help in achieving the full $\mathrm{SiC}$ technology potential. 


\section{Device Reliability}

$\mathrm{SiC}$ devices show great potential in the field of power electronics because of their high power handling capacity. $\mathrm{SiC}$ semiconductor materials account for the largest investment share in microelectronic design center and foundry R\&D [31]. However, $\left(D_{i t}\right)$ in the $\mathrm{SiC}-$ $\mathrm{SiO}_{2}$ system reduces the potential barrier between $\mathrm{SiC}$ and $\mathrm{SiO} 2$, thus resulting in increased carrier injection in the oxide. The stability of the $\mathrm{SiC}$ and $\mathrm{SiO}_{2}$ interface is yet to reach that of the $\mathrm{Si}$ and $\mathrm{SiO}_{2}$ stability due to the inherited small conduction band offset $[195,196]$. Microtubules, dislocations, grain boundaries, and epitaxial defects in $\mathrm{SiC}$ wafers and epitaxial layers have also been shown to reduce the critical breakdown electric field, leading to higher leakage currents and reduced device on-state performance $[195,197,198]$. Hence, reliability studies of $\mathrm{SiC}$ devices have become a focus of research, with increasing applications [195,199-201]. The substrate material, structure designs, and process technology affect the reliability of the device material.

The die-level failure mechanisms of $\mathrm{SiC}$ power MOSFET are mainly time-dependent dielectric breakdown (TDDB), accelerated life test high-temperature reverse bias (ALTHTRB), neutron-induced device breakdown, and avalanche breakdown [202]. TDDB occurs during the on-state mode; it happens when there is a wear-out of gate-oxide. ALT-HTRB is also based on the wear-out of gate-oxide. The ALT-HTRB occurs when the wear-out is due to the high electric field in the oxide layer of the JFET region, which is linked to the high drain bias. The neutron-induced device breakdown occurs due to exposure to the neutron, which causes random failures, and the failure worsens if the device is at a higher elevation on the earth. The avalanche breakdown is caused by high electric field stresses $[203,204]$. The most potential reliability issues of SiC MOSFETs are threshold voltage degradation [205], gate-oxide degradation [206], and body diode degradation [207].

\subsection{Threshold Voltage Degradation}

Threshold voltage degradation occurs due to the instability of the threshold voltage. According to [208], the oxide trap charging and its activation are the two main reasons behind the instability of threshold voltage. The density of the defects present in the device depends on the processing technology. The oxide trap charging occurs through the direct tunneling mechanism, which results in the shifting of the threshold voltage of the device at room temperature $[205,209]$. The threshold voltage is shifted to the negative side due to the presence of oxide traps with a positive charge, which results from the tunneling of electrons from the oxide, and it is shifted on the positive side when the positive oxide traps are neutralized by the electrons tunneling back into the oxide; this process of tunneling of electrons is generally an ad infinitum process [209].

If the negative shift is large, then there is an increase in blocking state leakage current, which will result in device failure if the increase in leakage current is very large. Similarly, if the positive shift is very large, then there will be an increase in the on-resistance of the device. The dependency of the stability of threshold voltage on the NO annealing, which is done after post-oxidation, has been observed $[205,209,210]$. The activation energy of the trap is observed to be about 1.1 to $1.2 \mathrm{eV}[209,211]$; hence, there is an increase in instability of the threshold voltage of the device when it is exposed to high temperature (above $100^{\circ} \mathrm{C}$ ) bias for an extended time period.

\subsection{Gate Oxide Degradation}

The degradation of the oxide layer is also a major issue regarding the reliability of SiC MOSFETs as the device has a thin layer of oxide [212]. The oxide layer of the SiC MOSFET is small when compared with the Si MOSFET when trying to achieve a reasonable value of threshold voltage and transconductance [213,214]. Additionally, the lower tunneling barrier between $\mathrm{SiC}$ and $\mathrm{SiO}_{2}$, i.e., $2.7 \mathrm{eV}$, makes the hopping of electrons from $\mathrm{SiC}$ to the oxide layer much easier [215].

The reliability of the gate oxide layer of SiC MOSFETs compared to Si devices can be discussed in three ways: (a) SiC MOSFETs have a lower inversion channel migration 
rate [195]. As a result, a higher electric field is required to achieve a smaller channel resistance. Hence, there exists a trade-off between smaller on-resistance and better gate oxide reliability, (b) a higher density of interface states [195,216] that appear at the SiC$\mathrm{SiO} 2$ interface reduces the barrier height, which results in the injection of more mobile hot carriers into the oxide from the doped $\mathrm{SiC}$. Hence, the non-equilibrium nature of the carriers induces dislocations in the gate oxide, and (c) the smaller conduction band offset between the $\mathrm{SiC}$ and $\mathrm{SiO}_{2}$ [217] introduces a higher Fowler-Nordheim tunneling current at a similar gate field and temperature. Therefore, the probability of time-dependent dielectric breakdown (TDDB) is higher. The relatively poor quality of the $\mathrm{SiC}$ and $\mathrm{SiO}_{2}$ interface is the main restraining factor for the extrinsic reliability. The presence of a high concentration carbon cluster makes the interface very rough, which further enhances the introduction of the traps and defects on the interface as well as near interface regions $[218,219]$.

There are two types of stresses that contribute to the degradation of the gate oxide layer, namely, high electric field stress and high-temperature stress [220]. An additional oxide trap near the interface is activated at high temperature and high electric field stress, which contributes to the trapping process [209]. The region of high electric field stress of UMOSFETs and DMOSFETs is shown in Figure 13 [195]. In UMOSFETs, an extremely high electric field is located in the oxide at the bottom of the trench [221]; the field concentration is more severe at the trench bottom and corner than at the lateral of the trench as the bottom of the trench is extended underneath the PN junction blocking voltage. In terms of controlling the electric field in the gate oxide, DMOSFET is the most promising $\mathrm{SiC}$ power MOSFET structure. The most widely studied indicators of gate oxide degradation include the Miller plateau time length [222], Miller plateau voltage amplitude [222,223], threshold voltage [209], drain leakage current, gate leakage current [224], and through-state resistance [222].

\subsection{Body Diode Degradation}

MOSFETs have a failure mode known as body diode degradation. This mode is a condition where forward current flows through the body diode of the MOSFET increase, and the resultant recombination energy of the electron-hole pair causes a defect called a "stacking defect", affecting the current path, which causes an increase in on-resistance and forward voltage of the body diode. The location of the body diode of the MOSFET is shown in Figure 14. The most prominent defect in $\mathrm{SiC}$ is the micropipe defect, where a hole through the top and bottom surface of the wafer is generated by lattice stacking misalignment. In addition to micropipes, there are many material defects. These defects can be broadly classified into wafer-level defects and epitaxial defects. Typically, $\mathrm{SiC}$ wafer defects are the nucleation point for epitaxial defects. Closed-core helical dislocation is an ordered crystalline defect, which is like a microtubule, and might continue to grow into the epitaxial layer depending on the epitaxial growth method. These defects can cause a decrease in the carrier life of the epitaxial layer [225].

The root cause of stacking faults at forward voltage is due to the expansion of baseplane dislocations (BPD) during forward conduction [226-228]. The coincident electrons and holes provide energy for the BPD to expand into a triangular stacking fault in the drift region [229]. The extended BPD penetrates through the epitaxial layer, creating a barrier for the conduction of multiple carriers, resulting in reduced carrier mobility [230].

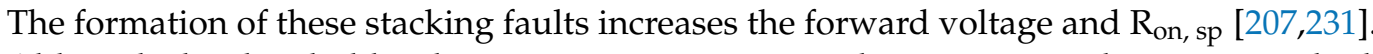
Although the threshold voltage remains constant in the post-stressed state, a gradual increase in state leakage is observed, and the electronic state generated by the expanding BPD acts as a charge generator. Hence, the expanding BPD acts as a charge generation center in the drift region [207]. 
a)

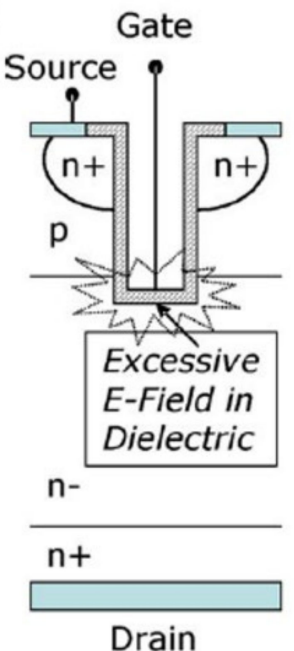

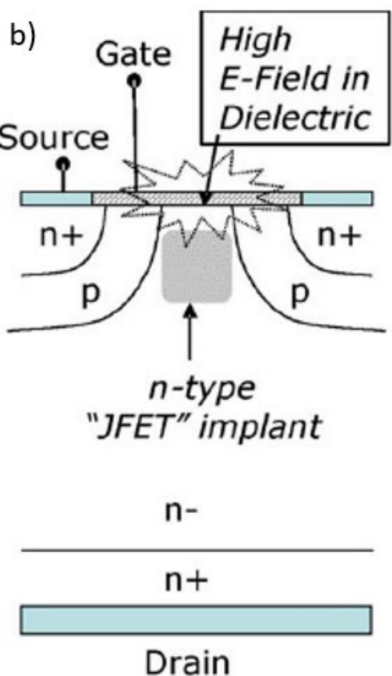

Figure 13. High electric field stress of (a) UMOSFETs and (b) DMOSFETs [195].

a)

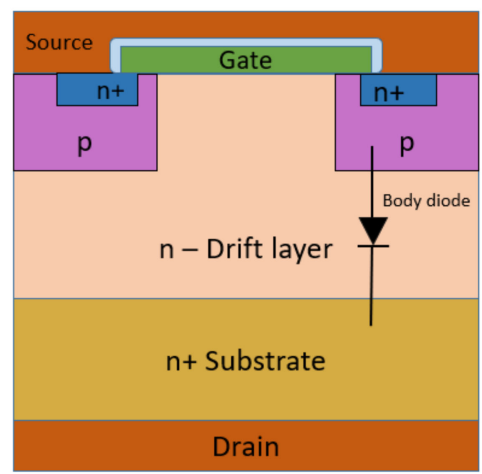

b)

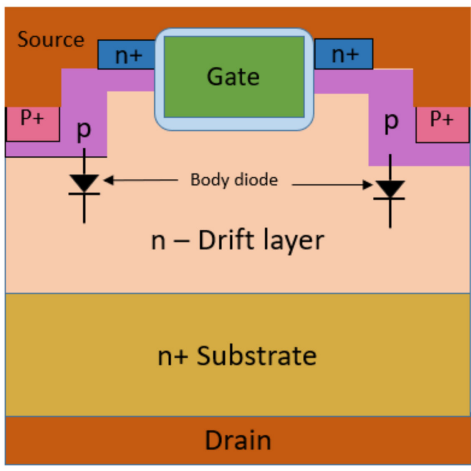

Figure 14. The location of body diode in (a) DMOSFETs and (b) UMOSFETs.

\section{Conclusions}

$\mathrm{SiC}$ power devices are widely used in power applications and have been researched extensively in various industries and academics. Along with the inherited superior material properties of $\mathrm{SiC}, \mathrm{SiC}$-based devices are able to be used in high speed, high voltage, and high-temperature operations. Hence, $\mathrm{SiC}$ power devices are employed in power converters, high-efficiency power inverters, and also in smart electric vehicles. This paper provides an extensive discussion about $\mathrm{SiC}$ materials, types of $\mathrm{SiC}$ power MOSFETs, their critical process steps, such as substrate growth, epitaxy layer, and ion implantation, and the impacts of critical process steps in improving the performance of the device. In addition, the reliability and failure mechanisms are also discussed. $\mathrm{SiC}$ power devices show great potential in achieving highly effective high-performance power applications.

Author Contributions: Data curation, C.L. and K.-H.C.; project administration, C.-W.S., W.-C.L. and K.-H.C.; supervision, M.-H.S., H.-C.K. and K.-Y.L.; writing-original draft, C.L., L.-H.H. and A.-C.L.; writing-review and editing, S.-C.C. and H.-C.K. All authors have read and agreed to the published version of the manuscript.

Funding: Ministry of Science and Technology, Taiwan. 110-2124-M-A49-003-, 108-2221-E-009-113MY3 and Hon Hai Research Center founding.

Institutional Review Board Statement: Not applicable.

Informed Consent Statement: Not applicable.

Data Availability Statement: Not applicable. 
Acknowledgments: The authors would like to thank the Industrial Technology Research Institute, Taiwan Semiconductor Research Institute, and the Semiconductor Research Center, Hon Hai Research Institute, for the helpful discussion.

Conflicts of Interest: The authors declare no conflict of interest.

\section{References}

1. Kassakian, J.G.; Jahns, T.M. Evolving and emerging applications of power electronics in systems. IEEE J. Emerg. Sel. Top. Power Electron. 2013, 1, 47-58. [CrossRef]

2. Van Wyk, J.D.; Lee, F.C. On a future for power electronics. IEEE J. Emerg. Sel. Top. Power Electron. 2013, 1, 59-72. [CrossRef]

3. Palmour, J.W. Silicon carbide power device development for industrial markets. In Proceedings of the 2014 IEEE International Electron Devices Meeting, San Francisco, CA, USA, 15-17 December 2014; pp. 1.1.1-1.1.8.

4. Millán, J.; Godignon, P.; Perpiñà, X.; Pérez-Tomás, A.; Rebollo, J. A Survey of Wide Bandgap Power Semiconductor Devices. IEEE Trans. Power Electron. 2014, 29, 2155-2163. [CrossRef]

5. Hertz, J. 2021 Starts With a Hot Streak for Silicon Carbide. 2021. Available online: https://www.allaboutcircuits.com/news/2021 -starts-with-a-hot-streak-for-silicon-carbide (accessed on 12 October 2021).

6. Biela, J.; Schweizer, M.; Waffler, S.; Kolar, J.W. SiC versus Si-Evaluation of Potentials for Performance Improvement of Inverter and DC-DC Converter Systems by SiC Power Semiconductors. IEEE Trans. Ind. Electron. 2011, 58, 2872-2882. [CrossRef]

7. Chow, T.-S. SiC and GaN High voltage Power switching devices. Mater. Sci. Forum 2000, 338-342, 1155-1160. [CrossRef]

8. Nakamura, T.; Sasagawa, M.; Nakano, Y.; Otsuka, T.; Miura, M. Large current SiC power devices for automobile applications. In Proceedings of the 2010 International Power Electronics Conference-ECCE ASIA, Sapporo, Japan, 21-24 June 2010; pp. 1023-1026.

9. Kimoto, T.; Cooper, J.A. Fundamentals of Silicon Carbide Technology: Growth, Characterization, Devices and Applications; John Wiley \& Sons: Hoboken, NJ, USA, 2014; Available online: https:/ / onlinelibrary.wiley.com/doi/book/10.1002/9781118313534 (accessed on 5 October 2021).

10. Saddow, S.E.; Agarwal, A.K. Advances in Silicon Carbide Processing and Applications; Artech House: Boston, MA, USA, 2004.

11. Kumar, V.; Kumar, S.; Maan, A.S.; Akhtar, J. Interface improvement of epitaxial $4 \mathrm{H}-\mathrm{SiC}$ based Schottky didoes by selective heavy ion irradiation. Available online: https:/ / link.springer.com/article/10.1007/s13204-020-01608-3 (accessed on 5 October 2021).

12. Zhang, Y. Comparison between competing requirements of $\mathrm{GaN}$ and $\mathrm{SiC}$ family of power switching devices. IOP Conf. Ser. Mater. Sci. Eng. 2020, 738, 012004. [CrossRef]

13. Berzelius, J.J. Untersuchungen über die Flussspathsäure und deren merkwürdigsten Verbindungen. Ann. Der Phys. 1824, 80, 1-22. [CrossRef]

14. Cheung, R. Silicon Carbide Microelectromechanical Systems for Harsh Environments; World Scientific: Singapore, 2006.

15. Gachovska, T.K.; Hudgins, J.L. SiC and GaN Power Semiconductor Devices. In Power Electronics Handbook; Elsevier: Amsterdam, The Netherlands, 2018; pp. 95-155.

16. Jian, J.; Sun, J. A Review of Recent Progress on Silicon Carbide for Photoelectrochemical Water Splitting. Sol. RRL 2020, 4, 2000111. [CrossRef]

17. Palmour, J.; Singh, R.; Glass, R.; Kordina, O.; Carter, C. Silicon carbide for power devices. In Proceedings of the 9th International Symposium on Power Semiconductor Devices and IC's, Weimar, Germany, 26-29 May 1997; pp. 25-32.

18. Itoh, A.; Akita, H.; Kimoto, T.; Matsunami, H. High-quality 4H-SiC homoepitaxial layers grown by step-controlled epitaxy. Appl. Phys. Lett. 1994, 65, 1400-1402. [CrossRef]

19. Konstantinov, A.; Wahab, Q.; Nordell, N.; Lindefelt, U. Ionization rates and critical fields in 4 H silicon carbide. Appl. Phys. Lett. 1997, 71, 90-92. [CrossRef]

20. Wijesundara, M.; Azevedo, R. Silicon Carbide Microsystems for Harsh Environments; Springer Science \& Business Media: Berlin/Heidelberg, Germany, 2011; Volume 22.

21. Neudeck, P.G. Silicon Carbide Technology. The VLSI Handbook, 20061800. 2006. Available online: https://scholar. googleusercontent.com/scholar?q=cache:dVVMlkQUxnwJ:scholar.google.com/\&hl=zh-TW\&as_sdt=0,5\&as_vis=1\&scioq= Silicon+Carbide+Technology.+The+VLSI+handbook (accessed on 5 October 2021).

22. Baliga, B.J. Silicon Carbide Power Devices; World Scientific: Singapore, 2006.

23. Patil, A.C. Silicon Carbide JFET Integrated Circuit Technology for High-Temperature Sensors. Ph.D. Thesis, Case Western Reserve University, Cleveland, OH, USA, 2009.

24. Shaddock, D.; Meyer, L.; Tucker, J.; Dasgupta, S.; Fillion, R.; Bronecke, P.; Yorinks, L.; Kraft, P. Advanced materials and structures for high power wide bandgap devices. In Proceedings of the Ninteenth Annual IEEE Semiconductor Thermal Measurement and Management Symposium, San Jose, CA, USA, 11-13 March 2003; pp. $42-47$.

25. Powell, A.R.; Rowland, L.B. SiC materials-progress, status, and potential roadblocks. Proc. IEEE 2002, 90, 942-955. [CrossRef]

26. Hefner, A.R.; Singh, R.; Lai, J.-S.; Berning, D.; Bouché, S.; Chapuy, C. SiC power diodes provide breakthrough performance for a wide range of applications. Power Electron. IEEE Trans. 2001, 16, 273-280. [CrossRef]

27. Mehregany, M.; Zorman, C.A.; Rajan, N.; Wu, C.H. Silicon carbide MEMS for harsh environments. Proc. IEEE 1998, 86, 1594-1609. [CrossRef] 
28. Mehregany, M.; Zorman, C.A. SiC MEMS: Opportunities and challenges for applications in harsh environments. Thin Solid Film. 1999, 355-356, 518-524. [CrossRef]

29. Shur, M. SiC Materials and Devices. 1 1; World Scientific Publ.: Singapore, 2006.

30. Baliga, B.J. 1-Introduction. In Wide Bandgap Semiconductor Power Devices; Baliga, B.J., Ed.; Woodhead Publishing: Sawston, UK, 2019; pp. 1-19.

31. Vacca, G. Benefits and advantages of silicon carbide power devices over their silicon counterparts. Semicond. Compd. Adv. Silicon 2017, 12, 72-75.

32. Ayalew, T. SiC Semiconductor Devices Technology, Modeling and Simulation. Ph.D. Dissertation, Technischen Universität Wien, Vienna, Austria, 2004.

33. Wu, R.; Wen, J.; Yu, K.; Zhao, D. A discussion of SiC prospects in next electrical grid. In Proceedings of the 2012 Asia-Pacific Power and Energy Engineering Conference, Shanghai, China, 27-29 March 2012; pp. 1-4.

34. Barkhordarian, V.J.P.; Edition, I.M.-E. Power MOSFET Basics. Powerconversion and Intelligent Motion-English Edition 22.61996. Available online: http:/ / caxapa.ru/thumbs/804043/mosfet_basic.pdf (accessed on 9 October 2021).

35. She, X.; Huang, A.Q.; Lucía, Ó.; Ozpineci, B. Review of silicon carbide power devices and their applications. IEEE Trans. Ind. Electron. 2017, 64, 8193-8205. [CrossRef]

36. Wang, J.; Zhao, T.; Li, J.; Huang, A.Q.; Callanan, R.; Husna, F.; Agarwal, A. Characterization, modeling, and application of 10-kV $\mathrm{SiC}$ MOSFET. IEEE Trans. Electron Devices 2008, 55, 1798-1806. [CrossRef]

37. Li, X.Q.; Tone, K.; Cao, L.H.; Alexandrov, P.; Fursin, L.; Zhao, J.H. Theoretical and experimental study of $4 \mathrm{H}-\mathrm{SiC}$ junction edge termination. In Mater. Sci. Forum; Trans Tech Publications Ltd.: Zurich-Uetikon, Switzerland, 2000; pp. 1375-1378.

38. Guo, X.; Xun, Q.; Li, Z.; Du, S.J.M. Silicon carbide converters and MEMS devices for high-temperature power electronics: A critical review. Micromachines 2019, 10, 406. [CrossRef] [PubMed]

39. Yuan, X.; Laird, I.; Walder, S. Opportunities, Challenges, and Potential Solutions in the Application of Fast-Switching SiC Power Devices and Converters. IEEE Trans. Power Electron. 2021, 36, 3925-3945. [CrossRef]

40. Weitzel, C.E.; Palmour, J.W.; Carter, C.H.; Moore, K.; Nordquist, K.; Allen, S.; Thero, C.; Bhatnagar, M. Silicon carbide high-power devices. IEEE Trans. Electron Devices 1996, 43, 1732-1741. [CrossRef]

41. Chen, G.; Bai, S.; Liu, A.; Wang, L.; Huang, R.H.; Tao, Y.H.; Li, Y. Fabrication and Application of 1.7KV SiC-Schottky Diodes. Mater. Sci. Forum 2015, 821-823, 579-582. [CrossRef]

42. Wahab, Q.; Kimoto, T.; Ellison, A.; Hallin, C.; Tuominen, M.; Yakimova, R.; Henry, A.; Bergman, J.P.; Janzén, E. A 3 kV Schottky barrier diode in 4H-SiC. Appl. Phys. Lett. 1998, 72, 445-447. [CrossRef]

43. McGlothlin, H.M.; Morisette, D.T.; Cooper, J.A.; Melloch, M.R. 4 kV silicon carbide Schottky diodes for high-frequency switching applications. In Proceedings of the 1999 57th Annual Device Research Conference Digest (Cat. No.99TH8393), Santa Barbara, CA, USA, 23 June 1999; pp. 42-43.

44. Singh, R.; Cooper, J.A.; Melloch, M.R.; Chow, T.P.; Palmour, J.W. SiC power Schottky and PiN diodes. IEEE Trans. Electron Devices 2002, 49, 665-672. [CrossRef]

45. Vassilevski, K.; Nikitina, I.P.; Horsfall, A.B.; Wright, N.G.; O’Neill, A.G.; Hilton, K.P.; Munday, A.G.; Hydes, A.J.; Uren, M.J.; Johnson, C.M. High Voltage Silicon Carbide Schottky Diodes with Single Zone Junction Termination Extension. Mater. Sci. Forum 2007, 556-557, 873-876. [CrossRef]

46. Zhao, J.H.; Alexandrov, P.; Li, X. Demonstration of the first 10-kV 4H-SiC Schottky barrier diodes. IEEE Electron Device Lett. 2003, 24, 402-404. [CrossRef]

47. Brosselard, P.; Pérez-Tomás, A.; Hassan, J.; Camara, N.; Jordà, X.; Vellvehí, M.; Godignon, P.; Millán, J.; Bergman, J.P. Low loss, large area $4.5 \mathrm{kV}$ 4H-SiC PIN diodes with reduced forward voltage drift. Semicond. Sci. Technol. 2009, 24, 095004. [CrossRef]

48. Peters, D.; Bartsch, W.; Thomas, B.; Sommer, R. 6.5 kV SiC PiN Diodes with Improved Forward Characteristics. Mater. Sci. Forum 2010, 645-648, 901-904. [CrossRef]

49. Ivanov, P.A.; Levinshtein, M.E.; Palmour, J.W.; Das, M.K.; Hull, B.A. High power 4H-SiC PiN diodes (10 kV class) with record high carrier lifetime. Solid-State Electron. 2006, 50, 1368-1370. [CrossRef]

50. Okamoto, D.; Tanaka, Y.; Mizushima, T.; Yoshikawa, M.; Fujisawa, H.; Takenaka, K.; Harada, S.; Ogata, S.; Hayashi, T.; Izumi, T. 13-kV, 20-A 4H-SiC PiN diodes for power system applications. Mater. Sci. Forum 2014, 778, 855-858. [CrossRef]

51. Kaji, N.; Niwa, H.; Suda, J.; Kimoto, T. Ultrahigh-voltage SiC pin diodes with improved forward characteristics. IEEE Trans. Electron Devices 2014, 62, 374-381. [CrossRef]

52. Dahlquist, F.; Zetterling, C.-M.; Östling, M.; Rottner, K. Junction barrier Schottky diodes in 4H-SiC and 6H-SiC. Mater. Sci. Forum 1998, 264, 1061-1064. [CrossRef]

53. Ren, N.; Wang, J.; Sheng, K. Design and experimental study of 4H-SiC trenched junction barrier Schottky diodes. IEEE Trans. Electron Devices 2014, 61, 2459-2465. [CrossRef]

54. Dahlquist, F.; Svedberg, J.; Zetterling, C.M.; Ostling, M.; Breitholtz, B.; Lendenmann, H. A 2.8 kV, forward drop JBS diode with low leakage. Mater. Sci. Forum 2000, 338, 1179-1182. [CrossRef]

55. Hu, J.; Li, L.X.; Alexandrov, P.; Wang, X.H.; Zhao, J.H. 5 kV, 9.5 A SiC JBS diodes with non-uniform guard ring edge termination for high power switching application. Mater. Sci. Forum 2009, 600, 947-950. [CrossRef] 
56. Hull, B.A.; Sumakeris, J.J.; O’Loughlin, M.J.; Zhang, Q.J.; Richmond, J.; Powell, A.R.; Paisley, M.J.; Tsvetkov, V.F.; Hefner, A.; Rivera, A. Development of Large Area (up to $1.5 \mathrm{~cm}^{2}$ ) $4 \mathrm{H}-\mathrm{SiC} 10 \mathrm{kV}$ Junction Barrier Schottky Rectifiers. Mater. Sci. Forum 2009, 600, 931-934.

57. Cheng, L.; Sankin, I.; Bondarenko, V.; Mazzola, M.S.; Scofield, J.D.; Sheridan, D.C.; Martin, P.; Casady, J.R.; Casady, J.B. HighTemperature Operation of $50 \mathrm{~A}\left(1600 \mathrm{~A} / \mathrm{cm}^{2}\right), 600 \mathrm{~V} 4 \mathrm{H}-\mathrm{SiC}$ Vertical-Channel JFETs for High-Power Applications. Mater. Sci. Forum 2009, 600, 1055-1058.

58. Sheridan, D.; Ritenour, A.; Bondarenko, V.; Burks, P.; Casady, J. Record 2.8 m $\Omega$-cm 21.9 kV enhancement-mode SiC VJFETs. In Proceedings of the 2009 21st International Symposium on Power Semiconductor Devices \& IC's, Barcelona, Spain, 14-18 June 2009; pp. 335-338.

59. Veliadis, V.; Snook, M.; McNutt, T.; Hearne, H.; Potyraj, P.; Lelis, A.; Scozzie, C. A 2055-V (at 0.7 mA $\left./ \mathrm{cm}^{2}\right) 24-\mathrm{A}($ at 706 W/cm²) Normally On 4H-SiC JFET With 6.8- $\mathrm{mm}^{2}$ Active Area and Blocking-Voltage Capability Reaching the Material Limit. IEEE Electron Device Lett. 2008, 29, 1325-1327. [CrossRef]

60. Huang, C.-F.; Kan, C.-L.; Wu, T.-L.; Lee, M.-C.; Liu, Y.-Z.; Lee, K.-Y.; Zhao, F. 3510-v 390-m $\Omega^{*} \mathrm{~cm}^{2} 4$ h-sic lateral jfet on a semi-insulating substrate. IEEE Electron Device Lett. 2009, 30, 957-959. [CrossRef]

61. Lee, W.-S.; Chu, K.-W.; Huang, C.-F.; Lee, L.-S.; Tsai, M.-J.; Lee, K.-Y.; Zhao, F. Design and fabrication of 4H-SiC lateral high-voltage devices on a semi-insulating substrate. IEEE Trans. Electron Devices 2011, 59, 754-760. [CrossRef]

62. Sung, W.; Van Brunt, E.; Baliga, B.J.; Huang, A.Q. A comparative study of gate structures for 9.4-kV $4 \mathrm{H}-\mathrm{SiC}$ normally on vertical JFETs. IEEE Trans. Electron Devices 2012, 59, 2417-2423. [CrossRef]

63. Zhao, J.H.; Alexandrov, P.; Zhang, J.; Li, X. Fabrication and characterization of 11-kV normally off $4 \mathrm{H}-\mathrm{SiC}$ trenched-and-implanted vertical junction FET. IEEE Electron Device Lett. 2004, 25, 474-476. [CrossRef]

64. Matocha, K.; Stum, Z.; Arthur, S.; Dunne, G.; Stevanovic, L. 950 Volt 4H-SiC MOSFETs: DC and transient performance and gate oxide reliability. Mater. Sci. Forum 2009, 600, 1131-1134. [CrossRef]

65. Uchida, K.; Saitoh, Y.; Hiyoshi, T.; Masuda, T.; Wada, K.; Tamaso, H.; Hatayama, T.; Hiratsuka, K.; Tsuno, T.; Furumai, M. The optimised design and characterization of $1200 \mathrm{~V} / 2.0 \mathrm{~m} \Omega \mathrm{cm} 24 \mathrm{H}-\mathrm{SiC}$ V-groove trench MOSFETs. In Proceedings of the $2015 \mathrm{IEEE}$ 27th International Symposium on Power Semiconductor Devices \& IC's (ISPSD), Hong Kong, China, 10-14 May 2015; pp. 85-88.

66. Agarwal, A.K.; Casady, J.B.; Rowland, L.; Valek, W.; Brandt, C. 1400 V 4H-SiC Power MOSFETs. Mater. Sci. Forum 1998, 264, 989-992. [CrossRef]

67. Noborio, M.; Suda, J.; Kimoto, T. 1580-V-40-m $\Omega \cdot \mathrm{cm} 2$ Double-RESURF MOSFETs on $4 \mathrm{H}-\mathrm{SiC}\left(0001^{-}\right)$. IEEE Electron Device Lett. 2009, 30, 831-833. [CrossRef]

68. Spitz, J.; Melloch, M.; Cooper, J.; Capano, M. 2.6 kV 4H-SiC lateral DMOSFETs. IEEE Electron Device Lett. 1998, 19, 100-102. [CrossRef]

69. Harada, S.; Kobayashi, Y.; Ariyoshi, K.; Kojima, T.; Senzaki, J.; Tanaka, Y.; Okumura, H. 3.3-kV-class 4H-SiC MeV-implanted UMOSFET with reduced gate oxide field. IEEE Electron Device Lett. 2016, 37, 314-316. [CrossRef]

70. Allen, S.; Pala, V.; VanBrunt, E.; Hull, B.; Cheng, L.; Ryu, S.; Richmond, J.; O’Loughlin, M.; Burk, A.; Palmour, J. Next-generation planar SiC MOSFETs from $900 \mathrm{~V}$ to $15 \mathrm{kV}$. Mater. Sci. Forum 2015, 821, 701-704. [CrossRef]

71. Huang, C.-F.; Cooper, J.A. 4H-SiC npn bipolar junction transistors with BV/sub CEO/> 3200 V. In Proceedings of the 14 th International Symposium on Power Semiconductor Devices and ICs, Sante Fe, NM, USA, 7 June 2002; pp. 57-60.

72. Ghandi, R.; Buono, B.; Domeij, M.; Zetterling, C.-M.; Ostling, M. High-voltage $(2.8 \mathrm{kV})$ implantation-free $4 \mathrm{H}-\mathrm{SiC}$ BJTs with long-term stability of the current gain. IEEE Trans. Electron Devices 2011, 58, 2665-2669. [CrossRef]

73. Masuda, T.; Saito, Y.; Kumazawa, T.; Hatayama, T.; Harada, S. $0.63 \mathrm{~m} \Omega \mathrm{cm}^{2} \$ / 1170 \mathrm{~V} 4 \mathrm{H}-\mathrm{SiC}$ Super Junction V-Groove Trench MOSFET. In Proceedings of the 2018 IEEE International Electron Devices Meeting (IEDM), San Francisco, CA, USA, 1-5 December 2018; pp. 8.1.1-8.1.4.

74. Zhang, Q.; Burk, A.; Husna, F.; Callanan, R.; Agarwal, A.; Palmour, J.; Stahlbush, R.; Scozzie, C. 4H-SiC bipolar junction transistors: From research to development-A case study: 1200 V, 20 A, stable SiC BJTs with high blocking yield. In Proceedings of the 2009 21st International Symposium on Power Semiconductor Devices \& IC's, Barcelona, Spain, 14-18 June 2009; pp. 339-342.

75. Sundaresan, S.G.; Jeliazkov, S.; Grummel, B.; Singh, R. Rapidly maturing SiC junction transistors featuring current gain $(\beta)>130$, blocking voltages up to $2700 \mathrm{~V}$ and stable long-term operation. Mater. Sci. Forum 2014, 778, 1001-1004. [CrossRef]

76. Sundaresan, S.; Jeliazkov, S.; Grummel, B.; Singh, R. 10 kV SiC BJTs—Static, switching and reliability characteristics. In Proceedings of the 2013 25th International Symposium on Power Semiconductor Devices \& IC's (ISPSD), Kanazawa, Japan, 26-30 May 2013; pp. 303-306.

77. Salemi, A.; Elahipanah, H.; Jacobs, K.; Zetterling, C.-M.; Östling, M. 15 kV-class implantation-free 4H-SiC BJTs with record high current gain. IEEE Electron Device Lett. 2017, 39, 63-66. [CrossRef]

78. Paques, G.; Scharnholz, S.; Dheilly, N.; Planson, D.; De Doncker, R.W. High-voltage 4H-SiC thyristors with a graded etched junction termination extension. IEEE Electron Device Lett. 2011, 32, 1421-1423. [CrossRef]

79. Sundaresan, S.G.; Issa, H.; Veeredy, D.; Singh, R. Large area $>8$ kV SiC GTO thyristors with innovative anode-gate designs. Mater. Sci. Forum 2010, 645, 1021-1024. [CrossRef]

80. Sugawara, Y.; Takayama, D.; Asano, K.; Agarwal, A.; Ryu, S.; Palmour, J.; Ogata, S. 12.7 kV ultra high voltage SiC commutated gate turn-off thyristor: SICGT. In Proceedings of the 16th International Symposium on Power Semiconductor Devices and ICs, Kitakyushu, Japan, 24-27 May 2004; pp. 365-368. [CrossRef] 
81. Cheng, L.; Agarwal, A.K.; Capell, C.; O’Loughlin, M.; Lam, K.; Richmond, J.; Van Brunt, E.; Burk, A.; Palmour, J.W.; O’Brien, H. $20 \mathrm{kV}, 2 \mathrm{~cm} \mathrm{2,4H-SiC} \mathrm{gate} \mathrm{turn-off} \mathrm{thyristors} \mathrm{for} \mathrm{advanced} \mathrm{pulsed} \mathrm{power} \mathrm{applications.} \mathrm{In} \mathrm{Proceedings} \mathrm{of} \mathrm{the} 2013$ 19th IEEE Pulsed Power Conference (PPC), San Francisco, CA, USA, 16-21 June 2013; pp. 1-4.

82. Kumar, V.; Maan, A.S.; Akhtar, J. Barrier height inhomogeneities induced anomaly in thermal sensitivity of Ni/4H-SiC Schottky diode temperature sensor. J. Vac. Sci. Technol. B 2014, 32, 041203. [CrossRef]

83. Todorovic, M.H.; Carastro, F.; Schuetz, T.; Roesner, R.; Stevanovic, L.; Mandrusiak, G.; Rowden, B.; Tao, F.; Cioffi, P.; Nasadoski, J.; et al. SiC MW PV Inverter. In Proceedings of the PCIM Europe 2016; International Exhibition and Conference for Power Electronics, Intelligent Motion, Renewable Energy and Energy Management, Nuremberg, Germany, 10-12 May 2016; pp. 1-8.

84. Fujii, K.; Noto, Y.; Oshima, M.; Okuma, Y. 1-MW solar power inverter with boost converter using all SiC power module. In Proceedings of the 2015 17th European Conference on Power Electronics and Applications (EPE'15 ECCE-Europe), Geneva, Switzerland, 8-10 September 2015; pp. 1-10. [CrossRef]

85. About the SiC MOSFETs Modules in Tesla Model 3. 2018. Available online: https://www.pntpower.com/tesla-model-3-poweredby-st-microelectronics-sic-mosfets / (accessed on 5 October 2021).

86. Toyota to Trial New SiC Power Semiconductor Technology. 2015. Available online: http://newsroom.toyota.co.jp/en/detail/56 92153 (accessed on 5 October 2021).

87. Su, M.; Chen, C.; Sharma, S.; Kikuchi, J. Performance and cost considerations for SiC-based HEV traction inverter systems. In Proceedings of the 2015 IEEE 3rd Workshop on Wide Bandgap Power Devices and Applications (WiPDA), Blacksburg, VA, USA, 2-4 November 2015; pp. 347-350.

88. Ishikawa, K.; Yukutake, S.; Kono, Y.; Ogawa, K.; Kameshiro, N. Traction inverter that applies compact 3.3 kV/1200 A SiC hybrid module. In Proceedings of the 2014 International Power Electronics Conference (IPEC-Hiroshima 2014-ECCE ASIA), Hiroshima, Japan, 18-21 May 2014; pp. 2140-2144.

89. Das, M.; Capell, C.; Grider, D.; Leslie, S.; Ostop, J.; Raju, R.; Schutten, M.; Nasadoski, J.; Hefner, A. 10 kV, 120 A SiC half H-bridge power MOSFET modules suitable for high frequency, medium voltage applications. In Proceedings of the 2011 IEEE Energy Conversion Congress and Exposition, Phoenix, AZ, USA, 17-22 September 2011; pp. 2689-2692.

90. G2020 Series SiC 500-750kVA. Available online: https:/ /www.toshiba.com/tic/power-electronics/uninterruptible-powersystems/ three-phase/g2020-series-sic-500-to-750-kva (accessed on 5 October 2021).

91. Schwarzer, U.; Buschhorn, S.; Vogel, K. System benefits for solar inverters using SiC semiconductor modules. In Proceedings of the PCIM Europe 2014; International Exhibition and Conference for Power Electronics, Intelligent Motion, Renewable Energy and Energy Management, Nuremberg, Germany, 20-22 May 2014; pp. 1-8.

92. Wang, X.; Wen, H.; Zhu, Y. Review of SiC Power Devices for Electrical Power Systems: Characteristics, Protection, and Application. In Proceedings of the 2021 6th Asia Conference on Power and Electrical Engineering (ACPEE), Chongqing, China, 8-11 April 2021; pp. 1-5.

93. Do, T.V.; Li, K.; Trovão, J.P.; Boulon, L. Reviewing of Using Wide-bandgap Power Semiconductor Devices in Electric Vehicle Systems: From Component to System. In Proceedings of the 2020 IEEE Vehicle Power and Propulsion Conference (VPPC), Gijon, Spain, 18 November-16 December 2020; pp. 1-6.

94. Bhatti, G.; Mohan, H.; Rassiah, R.S. Towards the future of smart electric vehicles: Digital twin technology. Renew. Sustain. Energy Rev. 2021, 141, 110801. [CrossRef]

95. Emilio, M.D.P. SiC MOSFETs Replace IGBTs in EV Bidirectional Chargers. 2021. Available online: https://www. powerelectronicsnews.com/9-ebook-july-2021-sic-mosfets-replace-igbts-in-ev-bidirectional-chargers / (accessed on 5 October 2021).

96. Ji, S.Y.; Kojima, K.; Ishida, Y.; Tsuchida, H.; Yoshida, S.; Okumura, H. Low Resistivity, Thick Heavily Al-Doped 4H-SiC Epilayers Grown by Hot-Wall Chemical Vapor Deposition. Mater. Sci. Forum 2013, 740-742, 181-184. [CrossRef]

97. Wang, X.; Cooper, J.A. High-Voltage n-Channel IGBTs on Free-Standing 4H-SiC Epilayers. IEEE Trans. Electron Devices 2010, 57, 511-515. [CrossRef]

98. Nakamura, R.; Nakano, Y.; Aketa, M.; Noriaki, K.; Ino, K. 1200V 4H-SiC Trench Devices. In Proceedings of the PCIM Europe 2014; International Exhibition and Conference for Power Electronics, Intelligent Motion, Renewable Energy and Energy Management, Nuremberg, Germany, 20-22 May 2014; pp. 1-7.

99. Nakamura, T.; Nakano, Y.; Aketa, M.; Nakamura, R.; Mitani, S.; Sakairi, H.; Yokotsuji, Y. High performance SiC trench devices with ultra-low ron. In Proceedings of the 2011 International Electron Devices Meeting, Washington, DC, USA, 5-7 December 2011; pp. 26.25.21-26.25.23.

100. Na, J.; Cheon, J.; Kim, K. 4H-SiC Double Trench MOSFET with Split Heterojunction Gate for Improving Switching Characteristics. Materials 2021, 14, 3554. [CrossRef]

101. Zhang, M.; Wei, J.; Jiang, H.; Chen, K.J.; Cheng, C.-H.; Reliability, M. A New SiC Trench MOSFET Structure with Protruded p-Base for Low Oxide Field and Enhanced Switching Performance. IEEE Trans. Device Mater. Reliab. 2017, 17, 432-437. [CrossRef]

102. Kusumoto, O.; Ohoka, A.; Horikawa, N.; Tanaka, K.; Niwayama, M.; Uchida, M.; Kanzawa, Y.; Sawada, K.; Ueda, T. Reliability of Diode-Integrated SiC Power MOSFET(DioMOS). Microelectron. Reliab. 2016, 58, 158-163. [CrossRef]

103. Kuchuk, A.V.; Borowicz, P.; Wzorek, M.; Borysiewicz, M.; Ratajczak, R.; Golaszewska, K.; Kaminska, E.; Kladko, V.; Piotrowska, A. Ni-Based Ohmic Contacts to $n$-Type 4H-SiC: The Formation Mechanism and Thermal Stability. Adv. Condens. Matter Phys. 2016, 2016, 9273702. [CrossRef] 
104. Miyazawa, T.; Tsuchida, H. Point defect reduction and carrier lifetime improvement of Si- and C-face $4 \mathrm{H}-\mathrm{SiC}$ epilayers. J. Appl. Phys. 2013, 113, 083714. [CrossRef]

105. Lee, S.M.; Jang, Y.; Jung, J.; Yum, J.H.; Larsen, E.S.; Bielawski, C.W.; Wang, W.; Ryou, J.-H.; Kim, H.-S.; Cha, H.-Y.; et al Atomic-layer deposition of crystalline BeO on SiC. Appl. Surf. Sci. 2019, 469, 634-640. [CrossRef]

106. Yang, X.; Lee, B.; Misra, V. Electrical Characteristics of $\mathrm{SiO}_{2}$ Deposited by Atomic Layer Deposition on $4 \mathrm{H}-\mathrm{SiC}$ After Nitrous Oxide Anneal. IEEE Trans. Electron Devices 2016, 63, 2826-2830. [CrossRef]

107. Khosa, R.Y.; Thorsteinsson, E.B.; Winters, M.; Rorsman, N.; Karhu, R.; Hassan, J.; Sveinbjörnsson, E.Ö. Electrical characterization of amorphous $\mathrm{Al}_{2} \mathrm{O}_{3}$ dielectric films on n-type $4 \mathrm{H}-\mathrm{SiC}$. AIP Adv. 2018, 8, 025304. [CrossRef]

108. Jayawardhena, I.U.; Ramamurthy, R.P.; Morisette, D.; Ahyi, A.C.; Thorpe, R.; Kuroda, M.A.; Feldman, L.C.; Dhar, S. Effect of surface treatments on $\mathrm{ALD} \mathrm{Al} \mathrm{O}_{3} / 4 \mathrm{H}-\mathrm{SiC}$ metal-oxide-semiconductor field-effect transistors. J. Appl. Phys. 2021, $129,075702$. [CrossRef]

109. Kim, H.; Yun, H.J.; Choi, B.J. Investigation of fast and slow traps in atomic layer deposited AlN on 4H-SiC. Optik 2019, 184, 527-532. [CrossRef]

110. Mane, A.U.; Das, S.; Shenai, K.; Elam, J.W. 2D-Layered Transition Metal Dichalcogenides (LTMDCs) Growth by Atomic Layer Deposition (ALD) for MOS Gate Channel Applications. In Workshop Program; University of Maryland: College Park, MD, USA, 23 September 2014; p. 37.

111. Shahin, D.I.; Tadjer, M.J.; Wheeler, V.D.; Koehler, A.D.; Anderson, T.J.; Eddy, C.R., Jr.; Christou, A. Electrical characterization of ALD HfO2 high-k dielectrics on $\left(2^{-} 01\right) \beta-G a 2 O 3$. Appl. Phys. Lett. 2018, 112, 042107. [CrossRef]

112. Tzou, A.-J.; Chu, K.-H.; Lin, I.-F.; Østreng, E.; Fang, Y.-S.; Wu, X.-P.; Wu, B.-W.; Shen, C.-H.; Shieh, J.-M.; Yeh, W.-K. AlN surface passivation of GaN-based high electron mobility transistors by plasma-enhanced atomic layer deposition. Nanoscale Res. Lett. 2017, 12, 1-6. [CrossRef]

113. Wellmann, P.J. Review of SiC crystal growth technology. Semicond. Sci. Technol. 2018, 33, 103001. [CrossRef]

114. Wellmann, P.; Bickermann, M.; Hofmann, D.; Kadinski, L.; Selder, M.; Straubinger, T.; Winnacker, A.J. In situ visualization and analysis of silicon carbide physical vapor transport growth using digital X-ray imaging. J. Cryst. Growth 2000, 216, $263-272$. [CrossRef]

115. Wellmann, P.; Hofmann, D.; Kadinski, L.; Selder, M.; Straubinger, T.; Winnacker, A.J. Impact of source material on silicon carbide vapor transport growth process. J. Cryst. Growth 2001, 225, 312-316. [CrossRef]

116. Wellmann, P.; Herro, Z.; Winnacker, A.; Püsche, R.; Hundhausen, M.; Masri, P.; Kulik, A.; Bogdanov, M.; Karpov, S.; Ramm, M.J. In situ visualization of $\mathrm{SiC}$ physical vapor transport crystal growth. J. Cryst. Growth 2005, 275, e1807-e1812. [CrossRef]

117. Wellmann, P.; Neubauer, G.; Fahlbusch, L.; Salamon, M.; Uhlmann, N.J.C.R. Growth of SiC bulk crystals for application in power electronic devices-Process design, 2D and 3D X-ray in situ visualization and advanced doping. Cryst. Res. Technol. 2015, 50, 2-9. [CrossRef]

118. Wellmann, P.J. Power electronic semiconductor materials for automotive and energy saving applications-SiC, $\mathrm{GaN}, \mathrm{Ga} 2 \mathrm{O}_{3}$, and diamond. Z. Für Anorg. Und Allg. Chem. 2017, 643, 1312-1322. [CrossRef]

119. Wellmann, P.J.; Konias, K.; Hens, P.; Hock, R.; Magerl, A. In Situ Observation of Polytype Switches during SiC PVT Bulk Growth by High Energy X-Ray Diffraction. Mater. Sci. Forum 2009, 615, 23-26. [CrossRef]

120. Kimoto, T.; Nakazawa, S.; Hashimoto, K.; Matsunami, H. Reduction of doping and trap concentrations in $4 \mathrm{H}-\mathrm{SiC}$ epitaxial layers grown by chemical vapor deposition. Appl. Phys. Lett. 2001, 79, 2761-2763. [CrossRef]

121. Nishizawa, S.-i.; Pons, M. Numerical modeling of SiC-CVD in a horizontal hot-wall reactor. Microelectron. Eng. 2006, 83, 100-103. [CrossRef]

122. Danno, K.; Hashimoto, K.; Saitoh, H.; Kimoto, T.; Matsunami, H.J. Low-concentration deep traps in $4 \mathrm{H}-\mathrm{SiC}$ grown with high growth rate by chemical vapor deposition. Jpn. J. Appl. Phys. 2004, 43, L969. [CrossRef]

123. Tsuchida, H.; Kamata, I.; Miyazawa, T.; Ito, M.; Zhang, X.; Nagano, M. Recent advances in $4 \mathrm{H}-S i C$ epitaxy for high-voltage power devices. Mater. Sci. Semicond. Processing 2018, 78, 2-12. [CrossRef]

124. Larkin, D.J.; Neudeck, P.G.; Powell, J.A.; Matus, L.G.J.A.P.L. Site-competition epitaxy for superior silicon carbide electronics. Appl. Phys. Lett. 1994, 65, 1659-1661. [CrossRef]

125. Kimoto, T.; Cooper, J.A. Fundamentals of Silicon Carbide Technology; Wiley: Hoboken, NJ, USA, 2014; Chapter 6.

126. Cooper, J.A.J. Advances in SiC MOS technology. Phys. Status Solidi A 1997, 162, 305. [CrossRef]

127. Fiorenza, P.; Giannazzo, F.; Roccaforte, F. Characterization of SiO2/4H-SiC Interfaces in 4H-SiC MOSFETs: A Review. Energies 2019, 12, 2310. [CrossRef]

128. Dhar, S.; Haney, S.; Cheng, L.; Ryu, S.R.; Agarwal, A.; Yu, L.; Cheung, K. Inversion layer carrier concentration and mobility in 4H-SiC metal-oxide-semiconductor field-effect transistors. J. Appl. Phys. 2010, 108, 054509. [CrossRef]

129. Cheong, K.Y.; Moon, J.; Kim, H.; Bahng, W.; Kim, N.-K. Metal-oxide-semiconductor characteristics of thermally grown nitrided $\mathrm{SiO}_{2}$ thin film on $4 \mathrm{H}-\mathrm{SiC}$ in various $\mathrm{N}_{2} \mathrm{O}$ ambient. Thin Solid Film. 2010, 518, 3255-3259. [CrossRef]

130. Hatakeyama, T.; Kiuchi, Y.; Sometani, M.; Harada, S.; Okamoto, D.; Yano, H.; Yonezawa, Y.; Okumura, H. Characterization of traps at nitrided $\mathrm{SiO}_{2} / \mathrm{SiC}$ interfaces near the conduction band edge by using Hall effect measurements. Appl. Phys. Express 2017, 10, 046601. [CrossRef] 
131. Chung, G.Y.T.; Tin, C.C.; Williams, J.R.; McDonald, K.; Chanana, R.K.; Weller, R.A.; Pantelides, S.T.; Feldman, L.C.; Holland, O.W.; Das, M.K.; et al. Improved Inversion Channel Mobility for 4H-SiC MOSFETs Following High Temperature Anneals in Nitric Oxide. IEEE Electron Devices Lett. 2001, 22, 176-178. [CrossRef]

132. Fiorenza, P.; Giannazzo, F.; Frazzetto, A.; Roccaforte, F. Influence of the surface morphology on the channel mobility of lateral implanted $4 \mathrm{H}-\mathrm{SiC}(0001)$ metal-oxide-semiconductor field-effect transistors. J. Appl. Phys. 2012, 112, 084501. [CrossRef]

133. Dhar, S.; Ahyi, A.C.; Williams, J.R.; Ryu, S.H.; Agarwal, A.K. Temperature Dependence of Inversion Layer Carrier Concentration and Hall Mobility in 4H-SiC MOSFETs. Mater. Sci. Forum 2012, 717-720, 713-716. [CrossRef]

134. Kosugi, R.; Fukuda, K.; Arai, K. High Temperature Rapid Thermal Oxidation and Nitridation of $4 \mathrm{H}-\mathrm{SiC}$ in $\mathrm{Diluted} \mathrm{N}_{2} \mathrm{O}$ and $\mathrm{NO}$ Ambient. Mater. Sci. Forum 2005, 483-485, 669-672. [CrossRef]

135. Adappa, R.; Suryanarayana, K.; Hatwar, H.S.; Rao, M.R. Review of SiC based power semiconductor devices and their applications. In Proceedings of the 2019 2nd International Conference on Intelligent Computing, Instrumentation and Control Technologies (ICICICT), Kannur, India, 5-6 July 2019; pp. 1197-1202.

136. Duan, Z.; Fan, T.; Wen, X.; Zhang, D. Improved SiC power MOSFET model considering nonlinear junction capacitances. IEEE Trans. Power Electron. 2017, 33, 2509-2517. [CrossRef]

137. Power MOSFET Structure and Characteristics. 2018. Available online: https://toshiba.semicon-storage.com/info/docget.jsp? did=13413 (accessed on 5 October 2021).

138. Minamisawa, R.; Bartolf, H. Simulations and Fabrication of Novel 4H-SiC Nano Trench MOSFET Devices. Project A9.7. Available online: https://www.researchgate.net/profile/HolgerBartolf/publication/283643159_Simulations_and_Fabrication_ of_Novel_4H-SiC_Nano_Trench_MOSFET_Devices/links/564218f208aeacfd8937fe5c/Simulations-and-Fabrication-of-Novel4H-SiC-Nano-Trench-MOSFET-Devices.pdf (accessed on 5 October 2021).

139. Agarwal, A.; Baliga, B.J. Performance Enhancement of $2.3 \mathrm{kV} 4 \mathrm{H}-\mathrm{SiC}$ Planar-Gate MOSFETs Using Reduced Gate Oxide Thickness. IEEE Trans. Electron Devices 2021, 68, 5029-5033. [CrossRef]

140. Ryu, S.H.; Agarwal, A.; Richmond, J.; Das, M.; Lipkin, L.; Palmour, J.; Saks, N.; Williams, J. Large-area (3.3 mm $\times 3.3 \mathrm{~mm})$ power MOSFETs in 4H-SiC. In Materials Science Forum; Trans Tech Publications Ltd.: Zurich-Uetikon, Switzerland, 2002; pp. 1195-1198.

141. Baliga, B.J. Fundamentals of Power Semiconductor Devices; Springer Nature: Berlin/Heidelberg, Germany, 2019.

142. Peters, D.; Siemieniec, R.; Aichinger, T.; Basler, T.; Esteve, R.; Bergner, W.; Kueck, D. Performance and ruggedness of 1200 V SiC-Trench-MOSFET. In Proceedings of the 2017 29th International Symposium on Power Semiconductor Devices and IC's (ISPSD), Sapporo, Japan, 28 May-1 June 2017; pp. 239-242.

143. Palmour, J.W.; Carter, C.; Edmund, J.; Kong, H.-S. 6H-silicon carbide power devices for aerospace applications. In Proceedings of the Intersociety Energy Conversion Engineering Conference, 1 January 1993; Volume 1, pp. 249-254. Available online: https: //www.researchgate.net/publication/282675519_6H-silicon_carbide_power_devices_for_aerospace_applications (accessed on 5 October 2021).

144. Palmour, J.; Edmond, J.; Kong, H.; Carter, C., Jr. Vertical power devices in silicon carbide. In Institute of Physics Conference Series; Adam Hilger, Ltd.: Bristol, UK; Boston, MA, USA, 1994; pp. 499-502.

145. Tsuji, T.; Iwaya, M.; Onishi, Y. 1.2-kV SiC Trench MOSFET. Fuji Electr. Rev. 2016, 62, 218-221.

146. Khan, I.; Cooper, J.; Capano, M.; Isaacs-Smith, T.; Williams, J. High-voltage UMOSFETs in $4 \mathrm{H}$ SiC. In Proceedings of the 14th International Symposium on Power Semiconductor Devices and ICs, Sante Fe, NM, USA, 7 June 2002; pp. 157-160.

147. Ryu, S.-H.; Krishnaswami, S.; O'Loughlin, M.; Richmond, J.; Agarwal, A.; Palmour, J.; Heffier, A.R. 10 kV, 123 m $\Omega-c m^{2} 4 H-S i C$ Power DMOSFETs; IEEE: Piscataway, NJ, USA, 2004; Volume 41, pp. 47-48.

148. Wei, J.; Liu, S.; Yang, L.; Tang, L.; Lou, R.; Li, T.; Fang, J.; Li, S.; Zhang, C.; Sun, W. Investigations on the degradations of double-trench $\mathrm{SiC}$ power MOSFETs under repetitive avalanche stress. IEEE Trans. Electron Devices 2018, 66, 546-552. [CrossRef]

149. Sampath, M.; Morisette, D.; Cooper, J.A. Comparison of single-and double-trench UMOSFETs in 4H-SiC. Mater. Sci. Forum 2018, 924, 752-755. [CrossRef]

150. Harada, S.; Kato, M.; Kojima, T.; Ariyoshi, K.; Tanaka, Y.; Okumura, H. Determination of optimum structure of $4 \mathrm{H}-\mathrm{SiC}$ trench MOSFET. In Proceedings of the 2012 24th International Symposium on Power Semiconductor Devices and ICs, Bruges, Belgium, 3-7 June 2012; pp. 253-256.

151. Jiang, J.-Y.; Huang, C.-F.; Wu, T.-L.; Zhao, F. Simulation study of 4h-SiC trench MOSFETs with various gate structures. In Proceedings of the 2019 Electron Devices Technology and Manufacturing Conference (EDTM), Singapore, 12-15 March 2019; pp. 401-403.

152. Luo, X.; Liao, T.; Wei, J.; Fang, J.; Yang, F.; Zhang, B.J. A novel 4H-SiC trench MOSFET with double shielding structures and ultralow gate-drain charge. J. Semicond. 2019, 40, 052803. [CrossRef]

153. Li, X.; Tong, X.; Huang, A.Q.; Qiu, S.; She, X.; Deng, X.C.; Zhang, B. Shielded Gate SiC Trench Power MOSFET with Ultra-Low Switching Loss. Mater. Sci. Forum 2018, 924, 765-769. [CrossRef]

154. Zhang, Q.J.; Wang, G.; Doan, H.; Ryu, S.; Hull, B.; Young, J.; Allen, S.; Palmour, J. Latest results on 1200 V 4 H-SiC CIMOSFETs with R sp, on of $3.9 \mathrm{~m} \Omega \cdot \mathrm{cm}^{2}$ at $150{ }^{\circ} \mathrm{C}$. In Proceedings of the 2015 IEEE 27th International Symposium on Power Semiconductor Devices \& IC's (ISPSD), Hong Kong, China, 10-14 May 2015; pp. 89-92.

155. Lendenmann, H.; Bergman, P.; Dahlquist, F.; Hallin, C. Structure of recombination-induced stacking faults in high-voltage SiC pn junction. Mater. Sci. Forum 2002, 433, 901. 
156. Sung, W.; Baliga, a.B. Monolithically integrated 4H-SiC MOSFET and JBS diode (JBSFET) using a single ohmic/Schottky process scheme. IEEE Electron Device Lett. 2016, 37, 1605-1608. [CrossRef]

157. Jiang, H.; Wei, J.; Dai, X.; Ke, M.; Zheng, C.; Deviny, I. Silicon carbide split-gate MOSFET with merged Schottky barrier diode and reduced switching loss. In Proceedings of the 2016 28th International Symposium on Power Semiconductor Devices and ICs (ISPSD), Prague, Czech Republic, 12-16 June 2016; pp. 59-62.

158. Kawahara, K.; Hino, S.; Sadamatsu, K.; Nakao, Y.; Yamashiro, Y.; Yamamoto, Y.; Iwamatsu, T.; Nakata, S.; Tomohisa, S.; Yamakawa, S. $6.5 \mathrm{kV}$ Schottky-barrier-diode-embedded SiC-MOSFET for compact full-unipolar module. In Proceedings of the 201729 th International Symposium on Power Semiconductor Devices and IC's (ISPSD), Sapporo, Japan, 28 May-1 June 2017; pp. 41-44.

159. Hino, S.; Hatta, H.; Sadamatsu, K.; Nagahisa, Y.; Yamamoto, S.; Iwamatsu, T.; Yamamoto, Y.; Imaizumi, M.; Nakata, S.; Yamakawa, S. Demonstration of SiC-MOSFET embedding Schottky barrier diode for inactivation of parasitic body diode. Mater. Sci. Forum 2017, 897, 477-482. [CrossRef]

160. Jiang, H.; Wei, J.; Dai, X.; Zheng, C.; Ke, M.; Deng, X.; Sharma, Y.; Deviny, I.; Mawby, P. SiC MOSFET with built-in SBD for reduction of reverse recovery charge and switching loss in 10-kV applications. In Proceedings of the 2017 29th International Symposium on Power Semiconductor Devices and IC's (ISPSD), Sapporo, Japan, 28 May-1 June 2017; pp. 49-52.

161. Hsu, F.-J.; Yen, C.-T.; Hung, C.-C.; Hung, H.-T.; Lee, C.-Y.; Lee, L.-S.; Huang, Y.-F.; Chen, T.-L.; Chuang, P.-J. High efficiency high reliability $\mathrm{SiC}$ MOSFET with monolithically integrated Schottky rectifier. In Proceedings of the 2017 29th International Symposium on Power Semiconductor Devices and IC's (ISPSD), Sapporo, Japan, 28 May-1 June 2017; pp. 45-48.

162. Furukawa, M.; Kono, H.; Sano, K.; Yamaguchi, M.; Suzuki, H.; Misao, T.; Tchouangue, G. Improved reliability of 1.2 kV SiC MOSFET by preventing the intrinsic body diode operation. In Proceedings of the PCIM Europe digital days 2020; International Exhibition and Conference for Power Electronics, Intelligent Motion, Renewable Energy and Energy Management, Nuremberg, Germany, 7-8 July 2020; pp. 1-5.

163. Fujihira, T.J. Theory of semiconductor superjunction devices. IEEE Trans. Electron Devices 1997, 36, 6254. [CrossRef]

164. Vudumula, P.; Kotamraju, S. Design and Optimization of SiC Super-Junction MOSFET Using Vertical Variation Doping Profile. IEEE Trans. Electron Devices 2019, 66, 1402-1408. [CrossRef]

165. Chen, J.; Sun, W.; Zhang, L.; Zhu, J.; Lin, Y. A review of superjunction vertical diffused mosfet. IETE Tech. Rev. 2012, 29 , 44-52. [CrossRef]

166. Kosugi, R.; Sakuma, Y.; Kojima, K.; Itoh, S.; Nagata, A.; Yatsuo, T.; Tanaka, Y.; Okumura, H. Development of SiC super-junction (SJ) devices by multi-epitaxial growth. Mater. Sci. Forum 2014, 778, 845-850. [CrossRef]

167. Kosugi, R.; Sakuma, Y.; Kojima, K.; Itoh, S.; Nagata, A.; Yatsuo, T.; Tanaka, Y.; Okumura, H. Development of SiC super-junction (SJ) device by deep trench-filling epitaxial growth. Mater. Sci. Forum 2013, 74, 785-788. [CrossRef]

168. Kojima, K.; Nagata, A.; Ito, S.; Sakuma, Y.; Kosugi, R.; Tanaka, Y. Filling of deep trench by epitaxial SiC growth. Mater. Sci. Forum 2013, 740, 793-796. [CrossRef]

169. Kosugi, R.; Sakuma, Y.; Kojima, K.; Itoh, S.; Nagata, A.; Yatsuo, T.; Tanaka, Y.; Okumura, H. First experimental demonstration of $\mathrm{SiC}$ super-junction (SJ) structure by multi-epitaxial growth method. In Proceedings of the 2014 IEEE 26th International Symposium on Power Semiconductor Devices \& IC's (ISPSD), Waikoloa, HI, USA, 15-19 June 2014; pp. 346-349.

170. Adachi, K.; Johnson, M.; Ohashi, H.; Shinohe, T.; Kinoshita, K.; Arai, K. Comparison of Super-Junction Structures in 4H-SiC and Si for High Voltage Applications. Mater. Sci. Forum 2001, 353-356, 719-722. [CrossRef]

171. Yu, L.; Sheng, K.J.S.-s.e. Breaking the theoretical limit of SiC unipolar power device-A simulation study. In Proceedings of the 2005 International Semiconductor Device Research Symposium, Bethesda, MD, USA, 7-9 December 2005; pp. 42-43. [CrossRef]

172. Naugarhiya, A.; Wakhradkar, P.; Kondekar, P.N.; Patil, G.C.; Patrikar, R.M.J. Analytical model for 4H-SiC superjunction drift layer with anisotropic properties for ultrahigh-voltage applications. J. Comput. Electron. 2017, 16, 190-201. [CrossRef]

173. Yu, L.; Sheng, K. Modeling and optimal device design for $4 \mathrm{H}-\mathrm{SiC}$ super-junction devices. IEEE Trans. Electron Devices 2008, 55, 1961-1969. [CrossRef]

174. Masuda, T.; Kosugi, R.; Hiyoshi, T. 0.97 mwcm2/820 v 4 h-sic super junction v-groove trench mosfet. Mater. Sci. Forum 2017, 897, 483-488. [CrossRef]

175. Harada, S.; Kobayashi, Y.; Kyogoku, S.; Morimoto, T.; Tanaka, T.; Takei, M.; Okumura, H. First demonstration of dynamic characteristics for $\mathrm{SiC}$ superjunction MOSFET realized using multi-epitaxial growth method. In Proceedings of the 2018 IEEE International Electron Devices Meeting (IEDM), San Francisco, CA, USA, 1-5 December 2018; pp. 8.2.1-8.2.4.

176. Kobayashi, Y.; Kyogoku, S.; Morimoto, T.; Kumazawa, T.; Yamashiro, Y.; Takei, M.; Harada, S. High-temperature performance of $1.2 \mathrm{kV}$-class SiC super junction MOSFET. In Proceedings of the 2019 31st International Symposium on Power Semiconductor Devices and ICs (ISPSD), Shanghai, China, 19-23 May 2019; pp. 31-34.

177. Okada, M.; Kyogoku, S.; Kumazawa, T.; Saito, J.; Morimoto, T.; Takei, M.; Harada, S. Superior short-circuit performance of SiC superjunction MOSFET. In Proceedings of the 2020 32nd International Symposium on Power Semiconductor Devices and ICs (ISPSD), Vienna, Austria, 13-18 September 2020; pp. 70-73.

178. Chen, C.-Y.; Lai, Y.-K.; Lee, K.-Y.; Huang, C.-F.; Huang, S.-Y. Investigation of 3.3 kV 4H-SiC DC-FSJ MOSFET Structures. Micromachines 2021, 12, 756. [CrossRef]

179. Baba, M.; Tawara, T.; Morimoto, T.; Harada, S.; Takei, M.; Kimura, H. Ultra-Low Specific on-Resistance Achieved in 3.3 kV-Class SiC Superjunction MOSFET. In Proceedings of the 2021 33rd International Symposium on Power Semiconductor Devices and ICs (ISPSD), Nagoya, Japan, 30 May-3 June 2021; pp. 83-86. 
180. Sheridan, D.C.; Niu, G.; Merrett, J.N.; Cressler, J.D.; Ellis, C.; Tin, C.-C. Design and fabrication of planar guard ring termination for high-voltage SiC diodes. Solid-State Electron. 2000, 44, 1367-1372. [CrossRef]

181. Saxena, V.; Su, J.N.; Steckl, A.J. High-voltage Ni-and Pt-SiC Schottky diodes utilizing metal field plate termination. IEEE Trans. Electron Devices 1999, 46, 456-464. [CrossRef]

182. Tarplee, M.C.; Madangarli, V.P.; Zhang, Q.; Sudarshan, T.S. Design rules for field plate edge termination in SiC Schottky diodes. IEEE Trans. Electron Devices 2001, 48, 2659-2664. [CrossRef]

183. Singh, R.; Irvine, K.G.; Capell, D.C.; Richmond, J.T.; Berning, D.; Hefner, A.R.; Palmour, J.W. Large area, ultra-high voltage 4H-SiC pin rectifiers. IEEE Trans. Electron Devices 2002, 49, 2308-2316. [CrossRef]

184. Wang, X.; Cooper, J.A. Optimization of JTE edge terminations for $10 \mathrm{kV}$ power devices in 4 H-SiC. Mater. Sci. Forum 2004, 457, 1257-1262. [CrossRef]

185. Sheridan, D.C.; Niu, G.; Cressler, J.D. Design of single and multiple zone junction termination extension structures for SiC power devices. Solid-State Electron. 2001, 45, 1659-1664. [CrossRef]

186. Das, M.K.; Hull, B.A.; Richmond, J.T.; Heath, B.; Sumakeris, J.J.; Powell, A.R. Ultra high power 10 kV, 50 A SiC PiN diodes. In Proceedings of the ISPSD'05. The 17th International Symposium on Power Semiconductor Devices and ICs, Santa Barbara, CA, USA, 23-26 May 2005; pp. 299-302.

187. Onose, H.; Oikawa, S.; Yatsuo, T.; Kobayashi, Y. Over 2000 V FLR termination technologies for SiC high voltage devices. In Proceedings of the 12th International Symposium on Power Semiconductor Devices \& ICs. Proceedings (Cat. No. 00CH37094), Toulouse, France, 22-25 May 2000; pp. 245-248.

188. Hiyoshi, T.; Hori, T.; Suda, J.; Kimoto, T. Simulation and experimental study on the junction termination structure for high-voltage 4H-SiC PiN diodes. IEEE Trans. Electron Devices 2008, 55, 1841-1846. [CrossRef]

189. Sundaresan, S.; Marripelly, M.; Arshavsky, S.; Singh, R. 15 kV SiC PiN diodes achieve 95\% of avalanche limit and stable long-term operation. In Proceedings of the 2013 25th International Symposium on Power Semiconductor Devices \& IC's (ISPSD), Kanazawa, Japan, 26-30 May 2013; pp. 175-177.

190. Sung, W.; Baliga, B.J.; Huang, A.Q. Area-efficient bevel-edge termination techniques for SiC high-voltage devices. IEEE Trans. Electron Devices 2016, 63, 1630-1636. [CrossRef]

191. Pérez, R.; Tournier, D.; Pérez-Tomás, A.; Godignon, P.; Mestres, N.; Millán, J. Planar edge termination design and technology considerations for 1.7-kV 4H-SiC PiN diodes. IEEE Trans. Electron Devices 2005, 52, 2309-2316. [CrossRef]

192. Sugawara, Y.; Takayama, D.; AsanO, K.; Singh, R.; Palmour, J.; Hayashi, T. 12-19 kV 4H-SiC pin diodes with low power loss. In Proceedings of the 13th International Symposium on Power Semiconductor Devices \& ICs. IPSD’01 (IEEE Cat. No. 01CH37216), Osaka, Japan, 7 June 2001; pp. 27-30.

193. Kinoshita, K.; Hatakeyama, T.; Takikawa, O.; Yahata, A.; Shinohe, T. Guard ring assisted RESURF: A new termination structure providing stable and high breakdown voltage for $\mathrm{SiC}$ power devices. In Proceedings of the Proceedings of the 14th International Symposium on Power Semiconductor Devices and ICs, Sante Fe, NM, USA, 7 June 2002; pp. 253-256.

194. Mihaila, A.; Sundaramoorthy, V.; Minamisawa, R.; Knoll, L.; Bartolf, H.; Bianda, E.; Alfieri, G.; Rahimo, M. A novel edge termination for high voltage SiC devices. In Proceedings of the 2016 28th International Symposium on Power Semiconductor Devices and ICs (ISPSD), Prague, Czech Republic, 12-16 June 2016; pp. 223-226.

195. Singh, R. Reliability and performance limitations in SiC power devices. Microelectron. Reliab. 2006, 46, 713-730. [CrossRef]

196. Singh, R.; Hefner, A.R. Reliability of SiC MOS devices. Solid-State Electron. 2004, 48, 1717-1720. [CrossRef]

197. Neudeck, P.G.; Powell, J.A. Performance limiting micropipe defects in silicon carbide wafers. IEEE Electron Device Lett. 1994, 15, 63-65. [CrossRef]

198. Karoui, M.B.; Gharbi, R.; Alzaied, N.; Fathallah, M.; Tresso, E.; Scaltrito, L.; Ferrero, S. Effect of defects on electrical properties of 4H-SiC Schottky diodes. Mater. Sci. Eng. C 2008, 28, 799-804. [CrossRef]

199. Ni, Z.; Lyu, X.; Yadav, O.P.; Singh, B.N.; Zheng, S.; Cao, D. Overview of real-time lifetime prediction and extension for SiC power converters. IEEE Trans. Power Electron. 2019, 35, 7765-7794. [CrossRef]

200. Pu, S.; Yang, F.; Vankayalapati, B.; Akin, B. Aging Mechanisms and Accelerated Lifetime Tests for SiC MOSFETs: An Overview. IEEE J. Emerg. Sel. Top. Power Electron. 2021, 10, 1232-1254. [CrossRef]

201. Ngwashi, D.K.; Phung, L.V. Recent review on failures in silicon carbide power MOSFETs. Microelectron. Reliab. 2021, 123, 114169. [CrossRef]

202. Gajewski, D.A.; Hull, B.; Lichtenwalner, D.J.; Ryu, S.-H.; Bonelli, E.; Mustain, H.; Wang, G.; Allen, S.T.; Palmour, J.W. SiC power device reliability. In Proceedings of the 2016 IEEE International Integrated Reliability Workshop (IIRW), South Lake Tahoe, CA, USA, 9-13 October 2016; pp. 29-34.

203. Tsunenobu, K.; James, A.C. Device Processing of Silicon Carbide. In Fundamentals of Silicon Carbide Technology: Growth, Characterization, Devices and Applications: IEEE; Wiley-IEEE Press: Hoboken, NJ, USA, 2014; pp. 189-276. [CrossRef]

204. Yen, C.-T.; Lee, H.; Hung, C.; Lee, C.; Lee, L.; Hsu, F.; Chu, K. Oxide breakdown reliability of SiC MOSFET. In Proceedings of the 2019 IEEE Workshop on Wide Bandgap Power Devices and Applications in Asia (WiPDA Asia), Taipei, Taiwan, 23-25 May 2019; pp. 1-3.

205. Lelis, A.J.; Habersat, D.; Green, R.; Ogunniyi, A.; Gurfinkel, M.; Suehle, J.; Goldsman, N. Time dependence of bias-stress-induced $\mathrm{SiC}$ MOSFET threshold-voltage instability measurements. IEEE Trans. Electron Devices 2008, 55, 1835-1840. [CrossRef] 
206. Liangchun, C.Y.; Dunne, G.T.; Matocha, K.S.; Cheung, K.P.; Suehle, J.S.; Sheng, K.; Reliability, M. Reliability issues of SiC MOSFETs: A technology for high-temperature environments. IEEE Trans. Device Mater. Rel. 2011, 10, 418-426.

207. Agarwal, A.; Fatima, H.; Haney, S.; Ryu, S.-H. A new degradation mechanism in high-voltage SiC power MOSFETs. IEEE Electron Device Lett. 2007, 28, 587-589. [CrossRef]

208. Lelis, A.J.; Green, R.; Habersat, D.B. SiC MOSFET threshold-stability issues. Mater. Sci. Semicond. Process. $2018,78,32-37$. [CrossRef]

209. Lelis, A.J.; Green, R.; Habersat, D.B.; El, M. Basic mechanisms of threshold-voltage instability and implications for reliability testing of SiC MOSFETs. IEEE Trans. Electron Devices 2014, 62, 316-323. [CrossRef]

210. Yen, C.T.; Hung, C.C.; Hung, H.T.; Lee, C.Y.; Lee, L.S.; Huang, Y.F.; Hsu, F.J. Negative bias temperature instability of SiC MOSFET induced by interface trap assisted hole trapping. Appl. Phys. Lett. 2016, 108, 012106. [CrossRef]

211. Habersat, D.B.; Green, R.; Lelis, A.J. Temperature-dependent threshold stability of COTS SiC MOSFETs during gate switching. In Proceedings of the 2017 IEEE International Reliability Physics Symposium (IRPS), Monterey, CA, USA, 2-6 April 2017; pp. WB-4.1-WB-4.4.

212. Wang, J.; Jiang, X. Review and analysis of SiC MOSFETs' ruggedness and reliability. IET Power Electron. 2020, 13, 445-455. [CrossRef]

213. Tega, N.; Sato, S.; Shima, A.J.I.E.D.L. Comparison of extremely high-temperature characteristics of planar and three-dimensional SiC MOSFETs. IEEE Electron Device Lett. 2019, 40, 1382-1384. [CrossRef]

214. Baliga, B.J. Gallium Nitride and Silicon Carbide Power Devices; World Scientific Publishing Company: Singapore, 2016.

215. Agarwal, A.K.; Seshadri, S.; Rowland, L.B. Temperature dependence of Fowler-Nordheim current in $6 \mathrm{H}$-and $4 \mathrm{H}-\mathrm{SiC}$ MOS capacitors. IEEE Electron Device Lett. 1997, 18, 592-594. [CrossRef]

216. Gonzalez, J.O.; Wu, R.; Jahdi, S.; Alatise, O. Performance and reliability review of $650 \mathrm{~V}$ and $900 \mathrm{~V}$ silicon and SiC devices: MOSFETs, cascode JFETs and IGBTs. IEEE Trans. Ind. Electron. 2019, 67, 7375-7385. [CrossRef]

217. Yu, L.; Cheung, K.P.; Campbell, J.; Suehle, J.S.; Sheng, K. Oxide reliability of SiC MOS devices. In Proceedings of the 2008 IEEE International Integrated Reliability Workshop Final Report, South Lake Tahoe, CA, USA, 12-16 October 2008; pp. 141-144.

218. Chang, K.; Nuhfer, N.; Porter, L.; Wahab, Q. High-carbon concentrations at the silicon dioxide-Silicon carbide interface identified by electron energy loss spectroscopy. Appl. Phys. Lett. 2000, 77, 2186-2188. [CrossRef]

219. Zhang, C.X.; Zhang, E.X.; Fleetwood, D.M.; Schrimpf, R.D.; Dhar, S.; Ryu, S.-H.; Shen, X.; Pantelides, S.T. Origins of low-frequency noise and interface traps in 4H-SiC MOSFETs. IEEE Electron Device Lett. 2012, 34, 117-119. [CrossRef]

220. Jiang, X.; Wang, J.; Chen, J.; Yu, H.; Li, Z.; Shen, Z.J.; Electronics, S.T.i.P. Investigation on Degradation of SiC MOSFET under Accelerated Stress in PFC Converter. IEEE J. Emerg. Sel. Top. Power Electron. 2020, 9, 4299-4310. [CrossRef]

221. Sridevan, S.; McLarty, P.K.; Baliga, B.J. Analysis of gate dielectrics for SiC power UMOSFETs. In Proceedings of the 9th International Symposium on Power Semiconductor Devices and IC's, Weimar, Germany, 26-29 May 1997; pp. $153-156$.

222. Karki, U.; Peng, F.Z. Effect of gate-oxide degradation on electrical parameters of power MOSFETs. IEEE Trans. Power Electron. 2018, 33, 10764-10773. [CrossRef]

223. Ye, X.; Chen, C.; Wang, Y.; Zhai, G.; Vachtsevanos, G.J. Online condition monitoring of power MOSFET gate oxide degradation based on miller platform voltage. IEEE Trans. Power Electron. 2016, 32, 4776-4784. [CrossRef]

224. Ouaida, R.; Berthou, M.; León, J.; Perpiñà, X.; Oge, S.; Brosselard, P.; Joubert, C. Gate oxide degradation of SiC MOSFET in switching conditions. IEEE Electron Device Lett. 2014, 35, 1284-1286. [CrossRef]

225. Neudeck, P.G. Electrical impact of SiC structural crystal defects on high electric field devices. Mater. Sci. Forum 1999, 338-342, 1161-1166. [CrossRef]

226. Bergman, J.P.; Lendenmann, H.; Nilsson, P.Å.; Lindefelt, U.; Skytt, P. Crystal defects as source of anomalous forward voltage increase of 4H-SiC diodes. Mater. Sci. Forum 2001, 353, 299-302. [CrossRef]

227. Liu, J.; Skowronski, M.; Hallin, C.; Söderholm, R.; Lendenmann, H. Structure of recombination-induced stacking faults in high-voltage SiC p-n junctions. Appl. Phys. Lett. 2002, 80, 749-751. [CrossRef]

228. Skowronski, M.; Ha, S.J. Degradation of hexagonal silicon-carbide-based bipolar devices. J. Appl. Phys. 2006, 99, 1. [CrossRef]

229. Treu, M.; Rupp, R.; Sölkner, G. Reliability of SiC power devices and its influence on their commercialization-review, status, and remaining issues. In Proceedings of the 2010 IEEE International Reliability Physics Symposium, Anaheim, CA, USA, 2-6 May 2010; pp. 156-161.

230. Ishigaki, T.; Murata, T.; Kinoshita, K.; Morikawa, T.; Oda, T.; Fujita, R.; Konishi, K.; Mori, Y.; Shima, A. Analysis of degradation phenomena in bipolar degradation screening process for SiC-MOSFETs. In Proceedings of the 2019 31st International Symposium on Power Semiconductor Devices and ICs (ISPSD), Shanghai, China, 19-23 May 2019; pp. 259-262.

231. Konishi, K.; Fujita, R.; Shima, A.; Shimamoto, Y. Modeling of stacking fault expansion velocity of body diode in $4 \mathrm{H}-\mathrm{SiC} \mathrm{MOSFET}$. Mater. Sci. Forum 2017, 897, 214-217. [CrossRef] 